\title{
Histological study of the effect of leflunomide on fundic mucosa of Adult male albino rat and the possible alleviating effect of $L$-arginine
}

\section{Original Article}

\author{
Mayada El Desouki Abd El Wahab El Husseiny, Shereen Shawky Abdel Aziz El \\ Abd, Kawther Abbas El Mihi, and Nadia Foad Elsayed Abo Hassan
}

Department of Histology, Faculty of Medicine, Tanta University, Tanta, Egypt

\begin{abstract}
Leflunomide is a disease-modifying anti-rheumatic drug used in the treatment of rheumatoid arthritis due to its anti-inflammatory and immunosuppressive effects. This study aimed to investigate the histological effect of leflunomide on the fundic gastric mucosa of adult male albino rat and the possible ameliorative role of the non-essential amino acid l-arginine. Fifty adult male albino rats were divided randomly into four main groups, group I (control group), group II treated with leflunomide, group III received the L-arginine and group IV received the leflunomide and the l-arginine concomitantly. The four groups were subdivided into two subgroups; the first received the drugs for two weeks and the second received the drugs for four weeks. At the end of the experiment, all rats were sacrificed; the fundic mucosa was dissected out and processed for light and electron microscopic study. Paraffin sections were stained with hematoxylin and eosin, periodic acid Schiff (PAS), Mallory trichrome and immunohistochemically for PCNA antibody. Leflunomide treated (group II) showed sloughing and desquamation of epithelial cells, superficial ulceration, and inflammatory cellular infiltration. Electron microscopic examination revealed absence of apical microvilli and coalescence of secretory granules. L-arginine ameliorated to some extent the histological changes occurred by leflunomide. It can be concluded that leflunomide exerts some histological changes on fundic gastric mucosa and co-administration of 1-arginine had ameliorating effects on the histological changes.
\end{abstract}

Key Words: Fundic, L-arginine, leflunomide, mucosa, rat

Revised: 20 January 2018, Accepted: 17 February 2018

Corresponding Author: mayada eldesouki elhusseiny, Tel.: 01093290630, E-mail: drmayadaelhusseiny@gmail.com

ISSN: $2536-9172$, Vol.1, No.2

\section{INTRODUCTION}

The gastric mucosa is continuously under stress by exposure to various physical and chemical injuries during the digestive process, the dietary contents or even abuse drug intake. The gastric mucosal barrier protects the mucosa from being digested by HCL, enzymes and erosive substances in gastric secretion. This mucosal barrier includes the compact epithelial lining of the stomach and their tight junctions, the mucus layer covering the surface epithelium, bicarbonate ions and the blood supply to the mucosa (Kossi et al., 2001 \& Cesar et al., 2006).

Leflunomide is a disease-modifying anti-rheumatic drug (DMARD) used in the treatment of active rheumatoid arthritis. It improves physical function and delays structural damage associated with the disease owing to its anti-inflammatory and immunosuppressive effects. It exerts its role by inhibiting the cell division. After ingestion of leflunomide; it is metabolized to teriflunomide named A771726, which has many side effects on different systems in the body especially the gastrointestinal tract causing gastritis that was aggravated to ulceration at high dose (Rossi, 2013).
The mechanism by which leflunomide induces gastritis and gastric ulcer depends on an interaction between the defense mechanisms of the stomach, gastric acid output and mucosal blood flow (Derosa et al., 2008). The gastric mucosal cells are in a process of continuous proliferation and apoptosis. Both these processes are in balance but if this balance is disturbed either due to increase apoptosis and/or decrease proliferation, mucosal injury will occur. Proliferating Cell Nuclear Antigen (PCNA) as a marker for cell proliferation that reaches its maximum level in the nucleus during late $\mathrm{G} 1 / \mathrm{S}$ phase of cell cycle and this indicates the onset of DNA synthesis (Tousson et al. 2014).

L-arginine is non-essential amino acid that has multiple biological properties e.g; the ability to stimulate anabolic hormone secretion, improving nitrogen balance, accelerating wound healing and increasing immunity (Cynober, 1994). Nitric oxide (NO) is produced from L-arginine by endothelial NO synthase and plays an important role in regulating endothelium-dependent vasodilatation, preventing the adhesion of blood cells and platelets along the lining endothelial cells and has scavenging effects against oxygen radical species (Morita et al, 2014). Many researchers demonstrate the benefits of 
L-arginine in alleviation of gastric ulcer induced by nonsteroidal anti-inflammatory drugs as indomethacin and ibuprofen (Khattab et al, 2001, Sanchez-Fidalgo et al. 2005 and Ajiboye et al. 2014). The aim of the present work was to study the histological and immunohistochemical effect of leflunomide on the fundic mucosa of adult male albino rat and the possible ameliorative role of $\mathrm{L}$-arginine.

\section{PATIENTS AND METHODS}

\section{Drugs:}

Leflunomide was obtained in the form of vials, each contained $1 \mathrm{gm}$ of the powder. The experimental dose of leflunomide was $10 \mathrm{mg} / \mathrm{kg}$ /day dissolved in distilled water, considering that each $1 \mathrm{ml}$ of distilled water contains 1.5 $\mathrm{mg} / \mathrm{kg} / \mathrm{of}$ leflunomide was given to the animal by gastric gavage once daily (Hagras et al.,2014).

L-arginine was in the form of white powder. The received dose of L-arginine was $200 \mathrm{mg} / \mathrm{kg} /$ day dissolved in $1 \mathrm{ml}$ of distilled water and was given orally by gastric gavage (Brzozowski et al., 1997 \& Kandeel et al., 2013). Both drugs were obtained from Sigma Chemical Company, Cairo, Egypt.

\section{Animals:}

The present study was carried out on fifty adult male albino rats, with an average weight of 120-150gm each. All the animals were housed in suitable clean properly ventilated cages under similar conditions in a $12 \mathrm{~h}$ light/ dark cycle and were fed on a similar commercial laboratory diet and water ad libitum. They were acclimatized to their environment for one week before starting the experiment that was approved by the local Ethical Committee of Faculty of Medicine, Tanta University (Nehru et al., 2007). All the medications were given orally prior to feeding in the morning.

\section{Experimental protocol}

\section{The animals were divided into four main groups:}

Group I (control group): consists of 20 rats subdivided equally into two subgroups;

Subgroup Ia kept without treatment to study the normal histological structure of fundic mucosa. Subgroup Ib received $1 \mathrm{ml}$ distilled water daily and orally.

Group II (leflunomide-treated group): included 10 rats that received leflunomide in a dose of $1.5 . \mathrm{mg}$ orally and daily.

Group III (L-arginine-treated group): included 10 rats that received L-arginine in a dose of $200 \mathrm{mg} / \mathrm{kg}$ orally and daily.
Group IV (Leflunomide and L-arginine-treated group): included 10 rats that received l-arginine and leflunomide at the same time with the same previous doses daily and orally. All animals were subdivided equally into two subgroup (A) and subgroup (B). Half of animals of the four groups were sacrificed after 2 weeks and the other half after 4 weeks.

After 24 hours from the last administration, the animals were fasted overnight and were anesthetized with intra peritoneal sodium thiopental injection as general anesthesia. The stomach was dissected out, opened at the greater curvature and washed with saline (Karthikeyan et al., 2009). The specimens were taken immediately from the glandular stomach below the limiting ridge and processed for histological, immunohistochemical examination and electron microscopic study.

\section{Light microscopic examination:}

Specimens from the fundus of stomach were immediately fixed in $10 \%$ neutral formol saline, dehydrated, cleared and embedded in paraffin. Sections of $5 \mu \mathrm{m}$ thickness were stained with haematoxylin and eosin (H\&E) for routine histological examination, Periodic Acid Schiff for detection of mucopolysaccharides and Mallory trichrome stain for detection of collagen fibers in the lamina propria and submucosa (Culling et al., 1985, Kiernan, 2008 and Suvarna et al., 2013).

\section{Immunohistochemical examination:}

It was carried by using avidin-biotin peroxidase technique for localization of proliferating cell nuclear antigen (PCNA) by using primary antibodies (anti-PCNA monoclonal antibody, dilution 1: 400-800, obtained from Lab Vision Company). Slides were counterstained with hematoxylin before mounting. The negative control sections were prepared by excluding the primary antibodies (Bancroft \& Gamble, 2008 and Sharma \& Gandhi, 2012).

\section{Electron microscopic examination:}

The specimens were fixed in $2.5 \%$ phosphate buffered glutaraldehyde, processed and embedded in epoxy resin by routine protocol. Semithin sections ( $1 \mu \mathrm{m}$ thick) were obtained and stained with 5\% toluidine blue and examined by light microscope. Ultrathin sections (80-100nm) were stained with uranyl acetate and lead citrate to be examined by (JEOL-JEM-100 SX electron microscope, Japan) electron microscope in E.M unit, Tanta, Faculty of Medicine, Tanta University (Bozzola \& Russell, 1999).

\section{Morphometric study:}

The image analysis software program (Image $\mathrm{j}$. 1.46version) was used to examine sections from the fundic mucosa in all groups. The optical density of PAS stain was 
measured in 5 randomly different microscopic fields for each specimen at a magnification power of $(x 400)$. The area percentage of collagen fibers with Mallory trichrome stain was measured in 5 randomly different microscopic fields for each specimen at a magnification power of (x400). The number of PCNA positive cells of the fundic glands were counted in 10 randomly selected different microscopic fields for each specimen at a magnification power of $(x 400)$

\section{Statistical analysis:}

The data obtained were analyzed using SPSS software version 13 (SPSS Inc., Chicago, IL, USA), then compared by one way analysis of variance (ANOVA) test followed by Tukey's test to compare different groups with the control group. The results were expressed as mean \pm standard deviation (SD). The differences were considered statistically significant if probability value $\mathrm{P}<0.05$ and highly significant if $\mathrm{P}<0.001$ and non-significant if $\mathrm{p}>0.05$ (Davies \& Crombie, 2009).

\section{RESULTS}

\section{$H \&$ E-stained sections:}

Group I (control group): The fundus of the stomach of control group showed thick mucosa separated from the underlying submucosa by muscularis mucosa. The lamina propria is occupied by tall straight densely packed gastric glands. Each one consists of isthmus, neck and base with narrow gastric pits. The gastric glands were lined by tall columnar mucous secreting cells having basal oval nuclei, low columnar mucous neck cells with basal flattened nuclei and large rounded parietal cells with acidophilic cytoplasm and central rounded nuclei (Fig.1).

\section{Group II (leflunomide-treated group):}

subgroup (IIA) showed separation of gastric glands, shortening of gastric pits, desquamation and sloughing of surface epithelial cells into the lumen. Congested blood vessels and inflammatory cellular infiltration were noticed in the submucosa (Fig.2a). Some parietal cells appeared with vacuolated cytoplasm while others with deep acidophilic cytoplasm and dark stained nuclei (Fig.2b). while subgroup (IIB) revealed affection of gastric mucosa in the form of focal areas of ulceration reaching the muscularis mucosa with detaching of fundic mucosa from the underlying muscularis mucosa, also there was wide separation between the fundic glands and widening of gastric pits (Fig.3a). Many parietal cells appeared ballooned and vacuolated with eccentric pyknotic nuclei (Fig.3b).

Group III (L-arginine-treated group): Examined sections of the fundus of the stomach of both subgroups
IIIA \& IIIB showed more or less the same histological structure of the fundus as that of the control group (Fig.4).

Group IV (L-arginine and leflunomide-treated group): Subgroup (IVA) revealed some improvement in the ultrastructural changes in the fundic mucosa than group II. It showed thick mucosa with tall, straight and packed gastric glands with variable gastric pits. Most of the lining cells appeared normal except few vacuolated parietal cells with mononuclear inflammatory cells were aggregated at the base of the glands in lamina propria (Fig.5a). Subgroup (IVB) showed thick mucosa containing straight packed glands with variable gastric pits and nearly normal appearance of their lining cells except presence of few ballooned vacuolated parietal cells (Fig.5b).

\section{Periodic Acid Schiff (PAS) stained sections:}

Examination of PAS stained sections obtained from the fundic mucosa of both group (I) and group (III) revealed PAS positive reaction covering the surface of gastric mucosa and extending downwards to fill the gastric pits \& isthmus of the glands while weak PAS positive reaction was observed at the base of the glands (Fig.6a). In subgroup (IIA) there was localized decrease of PAS reaction of the surface mucous coat, in the isthmus \& neck of the glands (Fig.6b), while sections of subgroup (IIB) showed marked decrease of the PAS reaction with areas of focal loss (Fig.6c). Sections from the fundic mucosa of subgroups (IVA \& IVB) revealed PAS positive reaction covering the intact surface epithelium and extending to fill the gastric pits (Figs.6d\&6e).

\section{Mallory trichrome stained sections:}

Examination of Mallory trichrome stained sections obtained from the fundic mucosa of both group I and group (III) revealed few collagen fibers between the fundic glands and in the submucosa (Fig.7a). Moderate increase in collagen fibers between the fundic glands, in the lamina propria especially at the base of the gland and in the submucosa was observed in subgroup (IIA) (Fig.7b), while sections of subgroup (IIB) showed marked deposition of collagen fibers inbetween the fundic gands, in the lamina propria at the base of glands and in the submucosa (Fig.7c). Sections from subgroups (IVA \& IVB) revealed few collagen fibers between fundic glands more or less similar to normal (Figs.7d\&7e).

\section{Immunohistochemical results:}

Examination of PCNA immunostained sections obtained from the fundic mucosa of both group (I) and group (III) revealed strong positive PCNA immune reaction in many nuclei of cells lining the isthmus and the 
neck of gastric glands (Fig.8a). Weak immune reaction in few nuclei of cells lining the isthmus and neck of the glands was observed in subgroup (IIA) (Fig.8b), whereas subgroup (IIB) revealed very weak PCNA reaction (Fig.8c). Sections of subgroup (IVA) showed strong PCNA immune reaction in many nuclei of cells of the isthmus and neck regions of gastric glands (Fig.8d), while subgroup (IVB) showed moderate increase in PCNA immune reaction (Fig.8e).

\section{Electron microscopic results:}

Group I (control group): Examination of ultrathin sections of the mucosa of fundic glands revealed surface columnar cells which were high columnar having apical microvilli, apical mucinogen granules, and basal oval nuclei with prominent nucleoli (Fig.9). Mucous neck cells appeared low columnar with apical microvilli, numerous apical secretory granules, basal rER and basal nuclei with prominent nucleoli (Fig.10). Parietal cells were large pyramidal containing intracellular canaliculi lined with long microvilli, numerous mitochondria having regular prominent cristae with rER in-between, Golgi cisternae and central spherical nucleus with normal chromatin distribution (Fig.11).

Group II (leflunomide-treated group): Examination of the surface columnar cells of subgroup (IIA) showed sparse apical microvilli and decreased amount of apical secretory granules, indentation of the nucleus, nucleolar margination and wide intercellular spaces (Fig.12). Mucous neck cells revealed coalescence of apical secretory granules and dilated rER (Fig.13). Parietal cells showed cytoplasmic vacuoles, normal mitochondria and shrunken indented nucleus with dilated perinuclear space (Fig.14). By TEM, subgroup (IIB) showed surface columnar cells with few apical microvilli, few apical secretory granules, cytoplasmic vacuoles and indented nucleus with nucleolar margination and wide perinuclear space (Fig.15). Mucous neck cells showed absence of apical microvilli, coalescence of mucous secretory granules, normal mitochondria, markedly dilated rER and perinuclear vacuolation (Fig.16). Parietal cells revealed flattening in its shape, dilatation of intracellular canaliculi, normal mitochondria, cytoplasmic vacuoles and basal nucleus with nucleolar margination (Fig.17).

Group III (L-arginine-treated group): Subgroups IIIA and IIIB revealed normal ultrastructural features of gastric mucosa.
Group IV (L-arginine and leflunomide treated group): Subgroup (IVA) revealed some improvement in the ultrastructural changes in the fundic mucosa. Most of surface columnar cells and mucous neck cells appeared normal with apical microvilli, apical mucous granules, basal rER and normal basal oval nucleus (Figs.18\&19). Most of parietal cells looked normal except for slight nuclear indentation (Fig.20). Electron microscopic examination of surface columnar cells, mucous neck cells and parietal cells of subgroup (IVB) revealed marked improvement (Fig. 21, 22 \& 23).

\section{Morphometric results and statistical analysis:}

1. Statistical results for the optical density of PAS stain:

The mean optical density of PAS stain in group (III) revealed non-significant change when compared with control group (I). The leflunomide treated subgroups IIA \& IIB revealed statistically highly significant decrease when compared with control group, while the L-arginine \& leflunomide treated subgroup (IVA) showed nonsignificant change from control group and subgroup (IVB) showed highly significant decrease compared with the control group (Table $1 \&$ Histogram 1).

2. Statistical results for the area percentage of collagen fibers with Mallory trichrome stain:

The mean area percentage of collagen in the L-arginine treated group (III) revealed non-significant change compared with control group (I). Subgroup (IIA) revealed non-significant increase compared with control group while subgroup (IIB) showed highly significant increase. Subgroups IVA \& IVB showed nonsignificant change compared with control group (Table 2 \& Histogram 2).

3. Statistical results for the PCNA immunoreactivity:

The mean number of PCNA positive cells in the fundic glands in the L-arginine treated group (III) revealed non-significant change compared with control (group I). Subgroups IIA \& IIB revealed highly significant decrease compared with control group. Subgroups IVA \& IVB showed significant increase compared with control group (Table $3 \&$ Histogram 3 ). 
Table (1): The mean optical density of PAS stain in different studied groups.

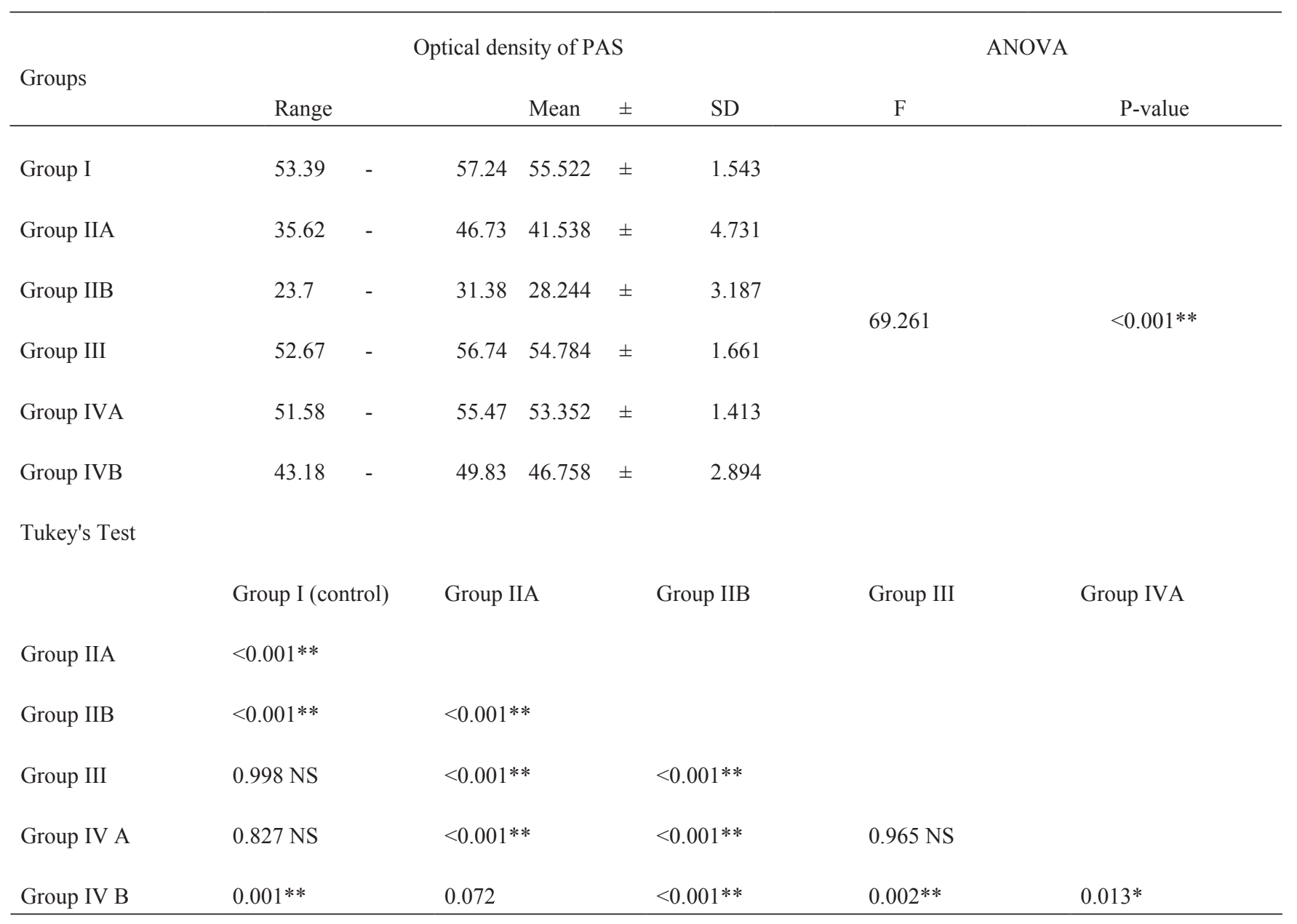

$\mathrm{SD}$ : standard deviation, $\mathrm{P}$ value $>0.05$ : non-significant, $\mathrm{P}$ value $<0.05$ : significant, $\mathrm{P}$ value $<0.001(*)$ : highly significant.

Histogram (1) : The mean optical density of PAS in different studied groups.

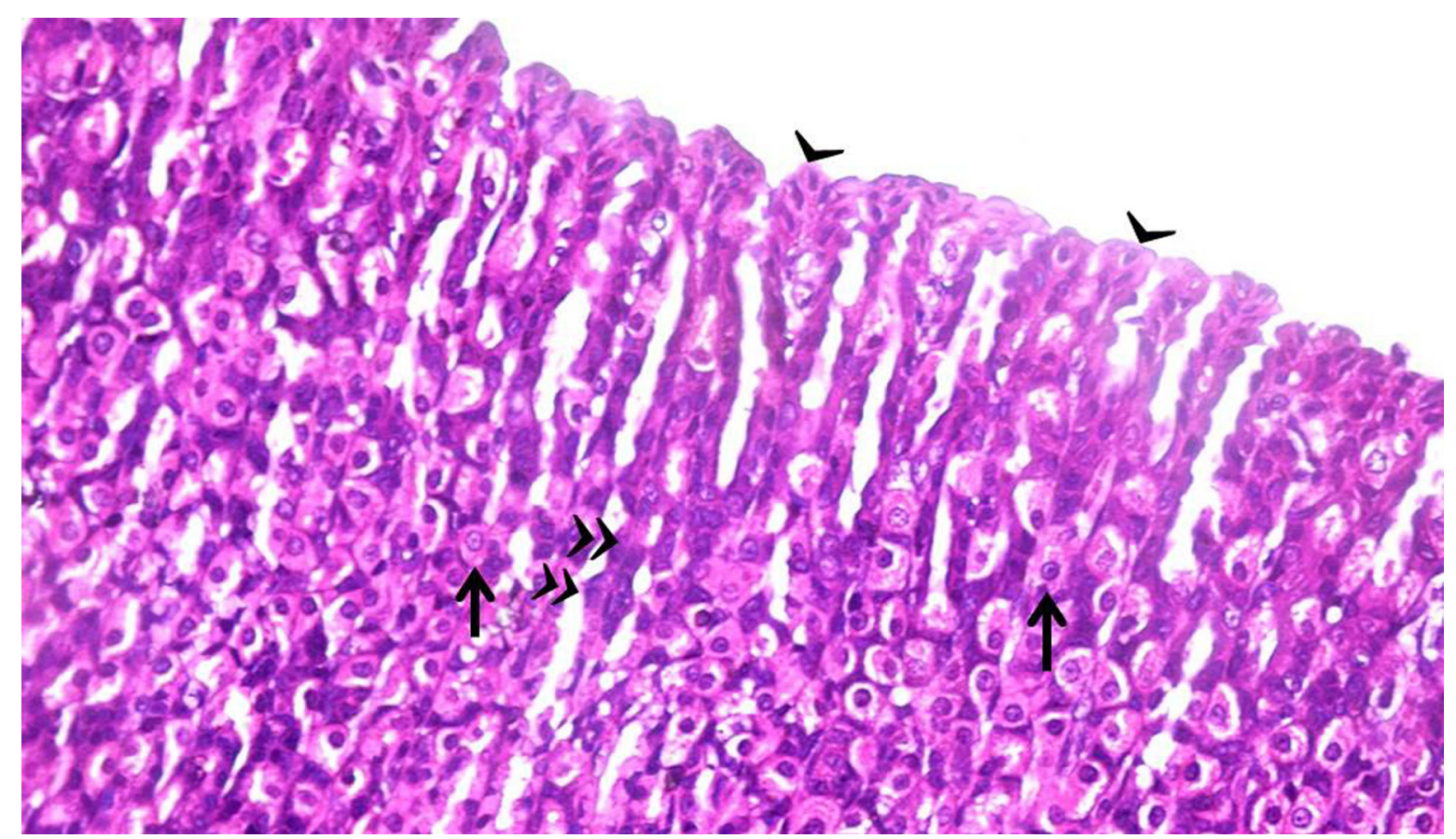


Table (2) : The mean area percentage of collagen with Mallory trichrome stain in different studied groups.

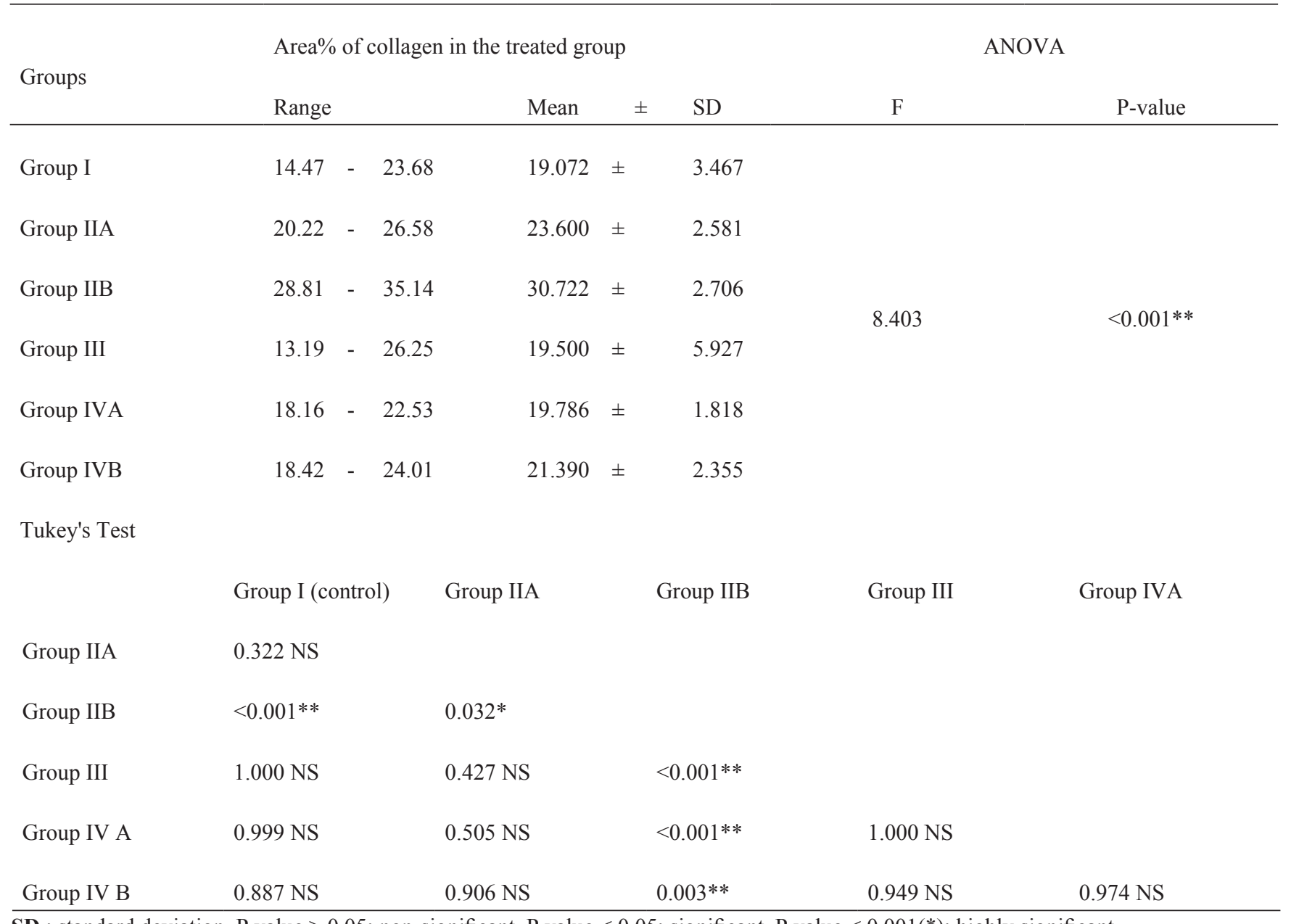

SD : standard deviation, $\mathrm{P}$ value $>0.05$ : non-significant, $\mathrm{P}$ value $<0.05$ : significant, $\mathrm{P}$ value $<0.001(*)$ : highly significant.

Histogram (2): The mean area percentage of collagen with Mallory trichrome stain in different studied groups.

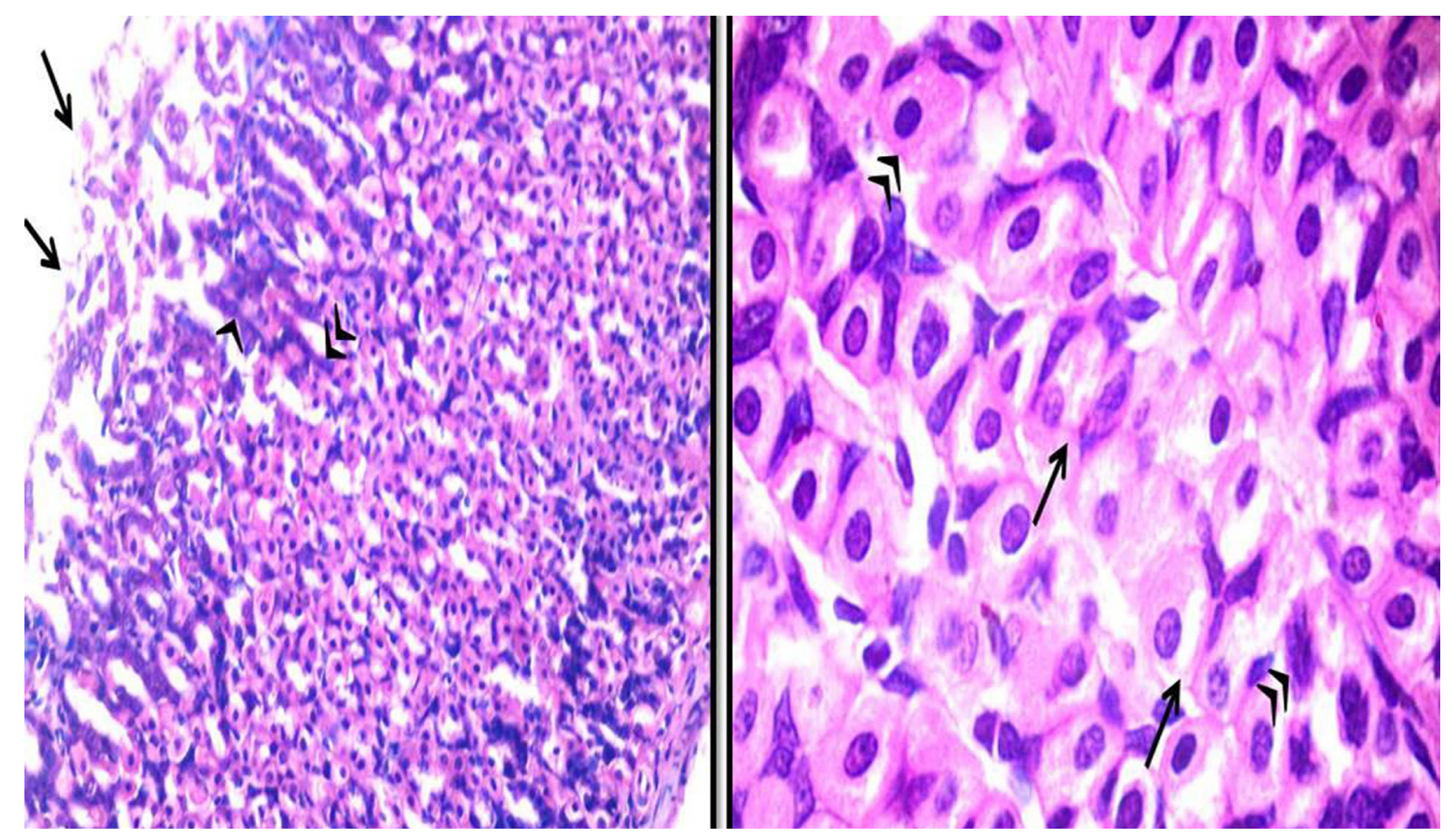


Table (3): The mean number of PCNA positive cells of the fundic mucosa in different studied groups.

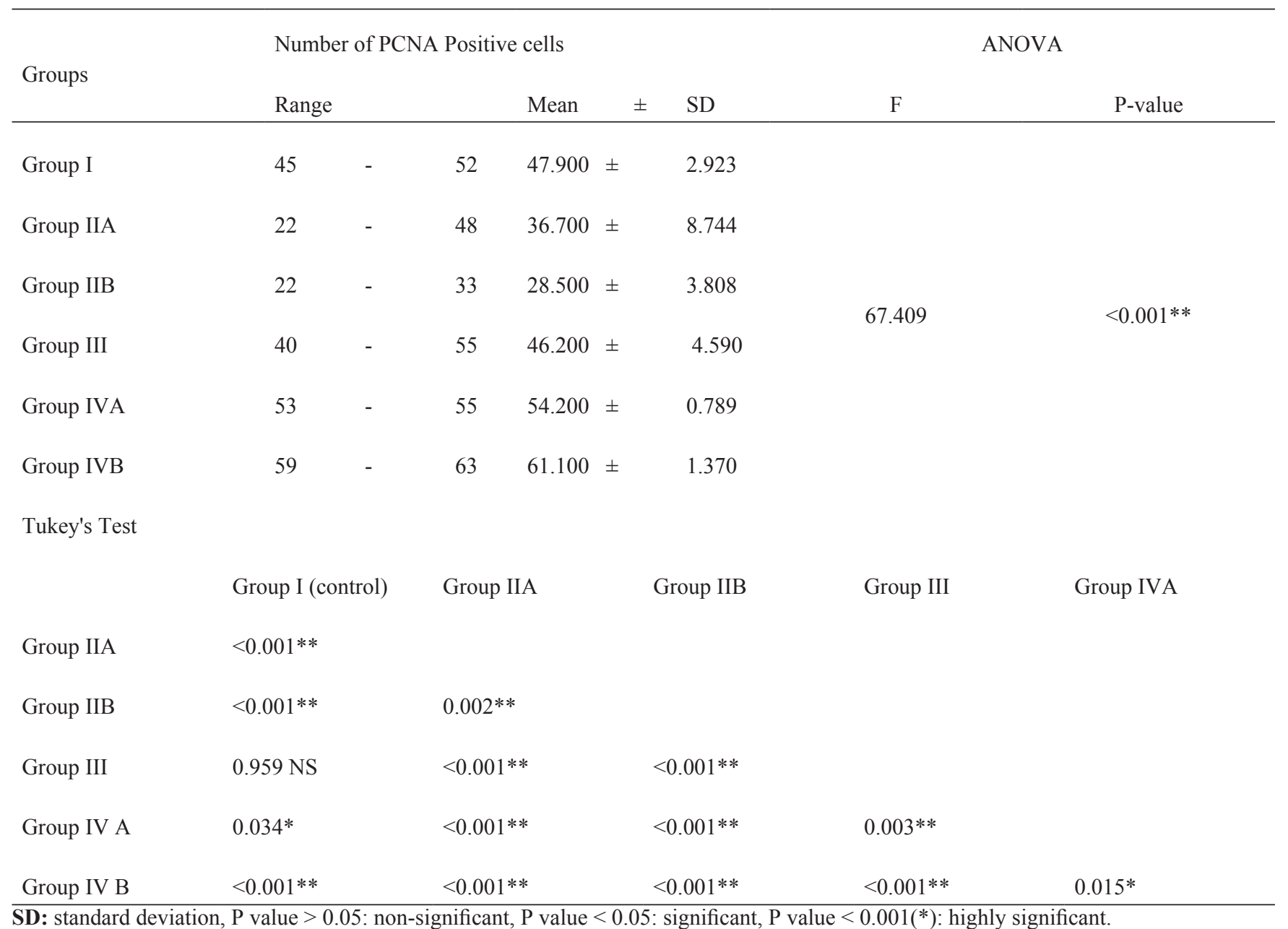

SD: standard deviation, $\mathrm{P}$ value $>0.05$ : non-significant, $\mathrm{P}$ value $<0.05$ : significant, $\mathrm{P}$ value $<0.001(*)$ : highly significant.

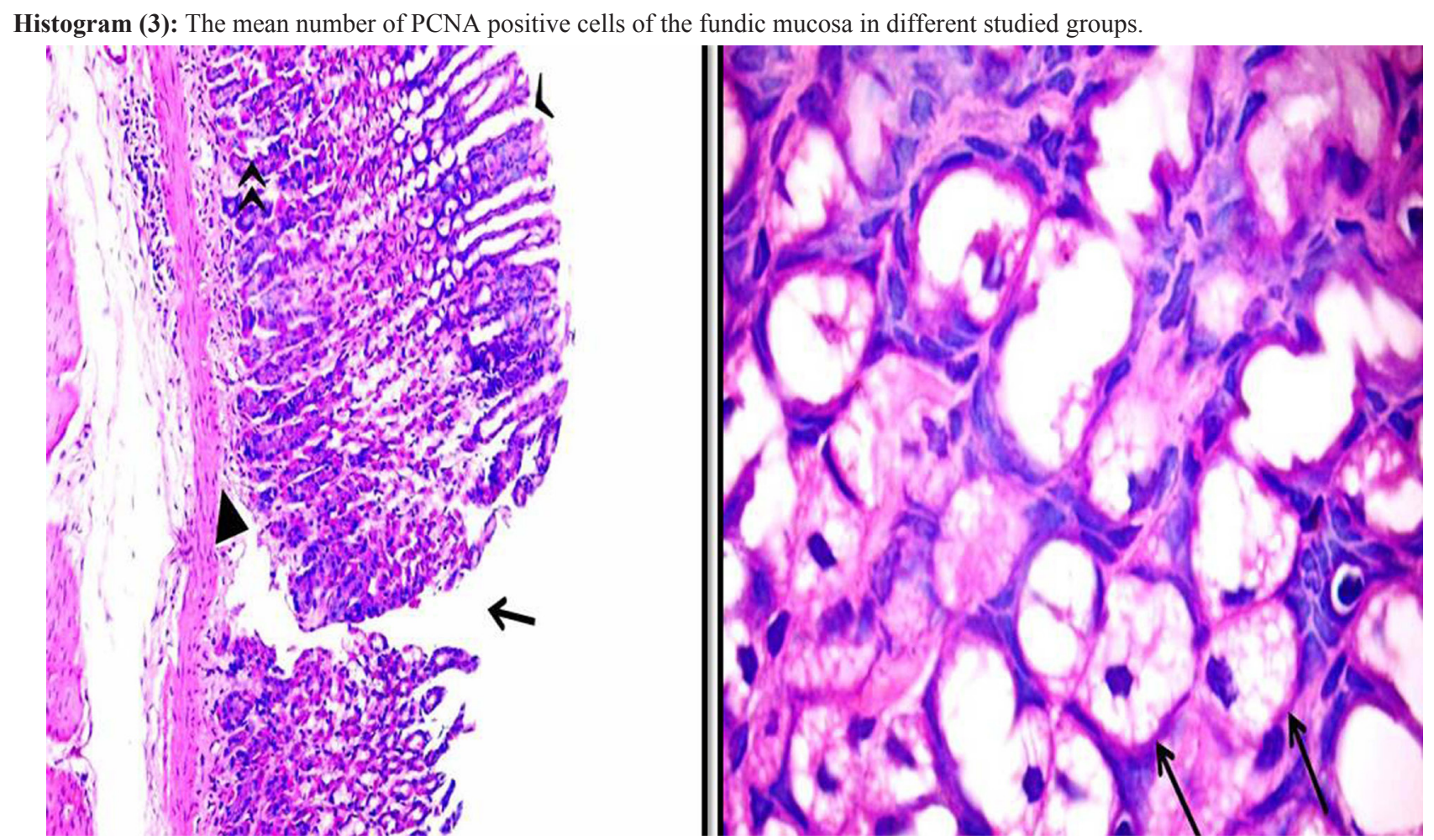




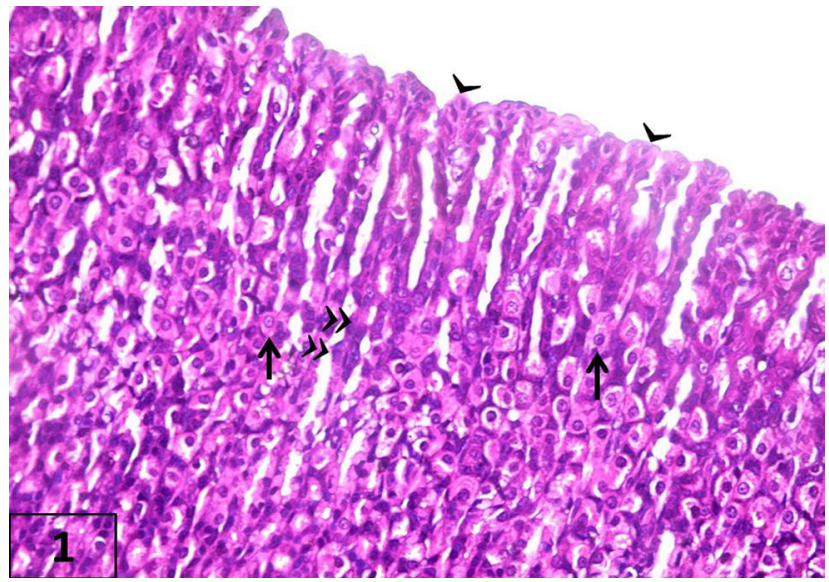

Fig. (1): A photomicrograph of the fundic gastric mucosa of the control group, showing long, straight, packed gastric glands lined with normal surface columnar cells with basal oval nuclei ( ), mucous neck cells with basal flattened nuclei (»)) and parietal cells with central rounded nuclei $(\rightarrow)$ (H\&E x 400)

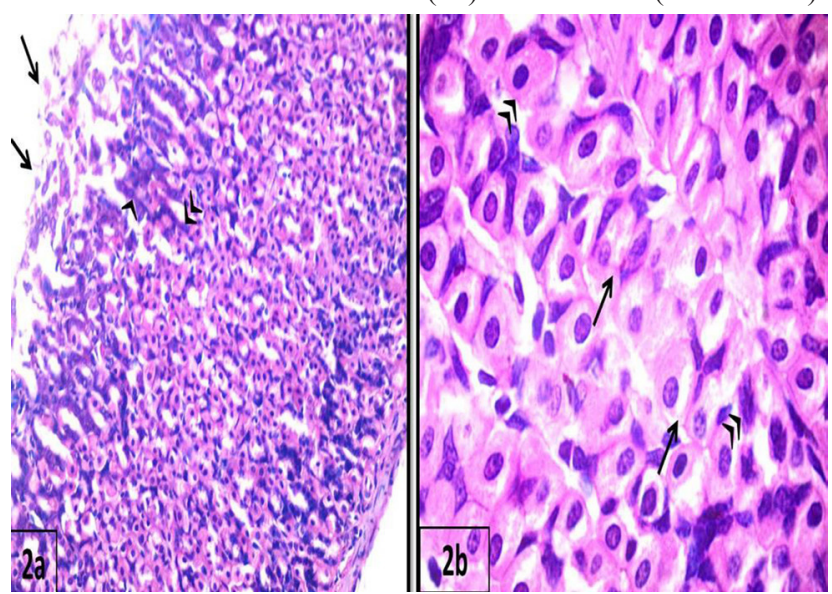

Fig. (2): A photomicrograph of the fundic gastric mucosa of subgroup IIA; (2a) showing separation in the gastric glands $(\triangleright)$, short gastric pits $(*)$, sloughing and desquamation of surface epithelial cells into the lumen $(\rightarrow)$ while $(2 b)$ showing parietal cells with vacuolated cytoplasm $(\rightarrow)$, others with deeply acidophilic cytoplasm and deeply stained nuclei (») (H\&E 2a x $400 \& 2 b \times 1000)$.
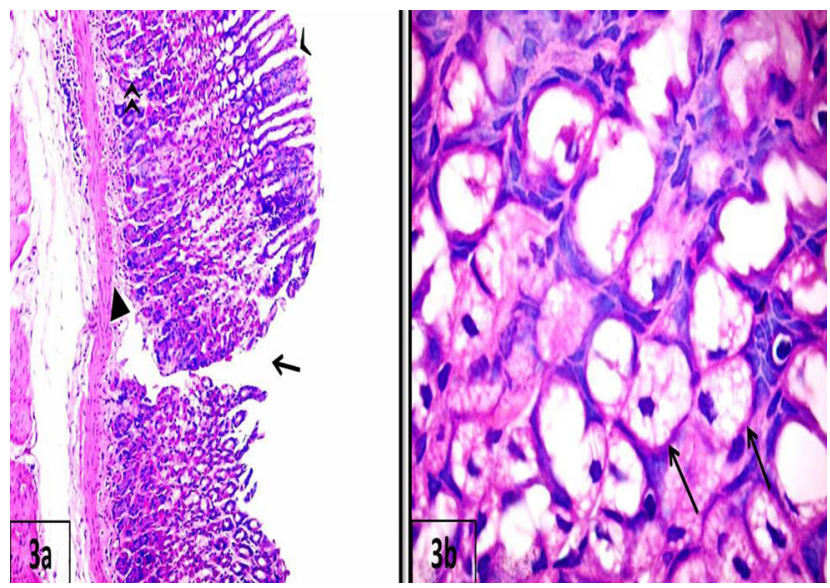

Fig. (3): A photomicrograph of subgroup IIB; (3a) showing deep ulceration $(\rightarrow)$ reaching the muscularis mucosa with detaching of fundic mucosa from the underlying muscularis mucosa $(\nabla)$. Notice: widening of gastric pits ( () and separation between fundic glands (») while (3b) showing marked ballooning \& vacuolations of parietal cells with eccentric pyknotic nuclei $(\rightarrow)$

(H\&E $3 \mathrm{a} \times 200 \& 3 \mathrm{~b} \times 1000)$.

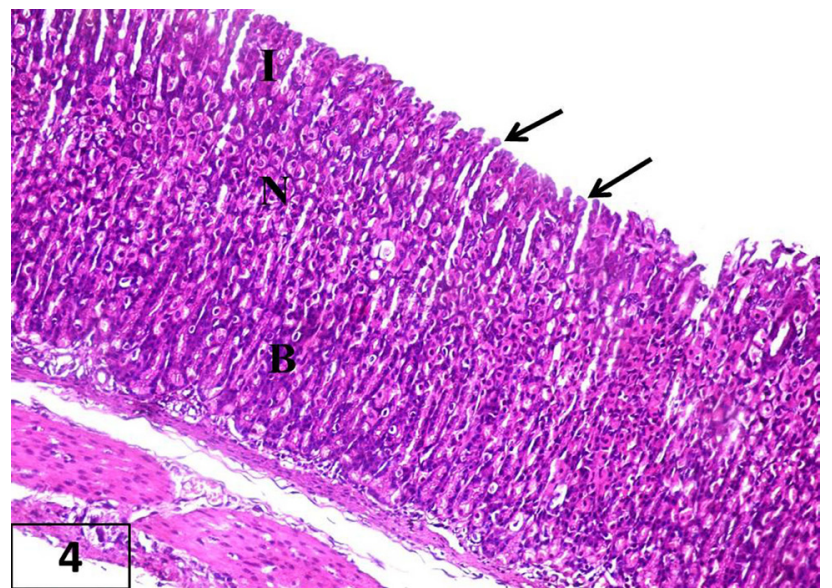

Fig. (4): A photomicrograph of subgroup IIIB, showing apparently normal mucosa $(\rightarrow)$ consisting of packed glands formed of isthmus (I), neck (N) and base (B) (H\&E x 200).

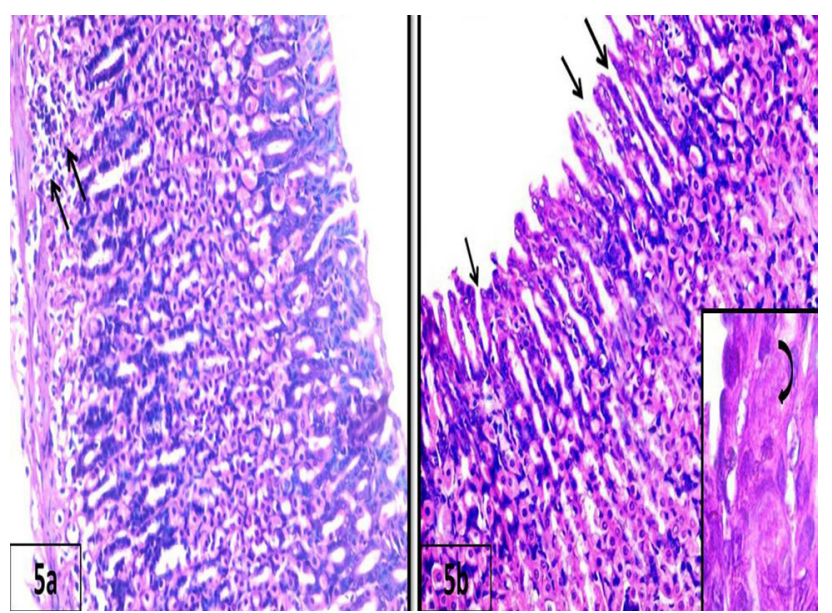

Fig (5): A photomicrograph of subgroup IVA; (5a) showing thick mucosa with variable gastric pits, some parietal cells appeared with vacuolated cytoplasm ( )and aggregated inflammatory cells are noticed in the base of lamina propria $(\rightarrow)$ while $(5 b)$ showing straight packed, parallel gastric glands with variable gastric pits $(\rightarrow)$. The inset shows ballooned parietal cells (curved arrow) ( H\&E 5a \& 5b x 400. (Inset $x$ 1000)). 


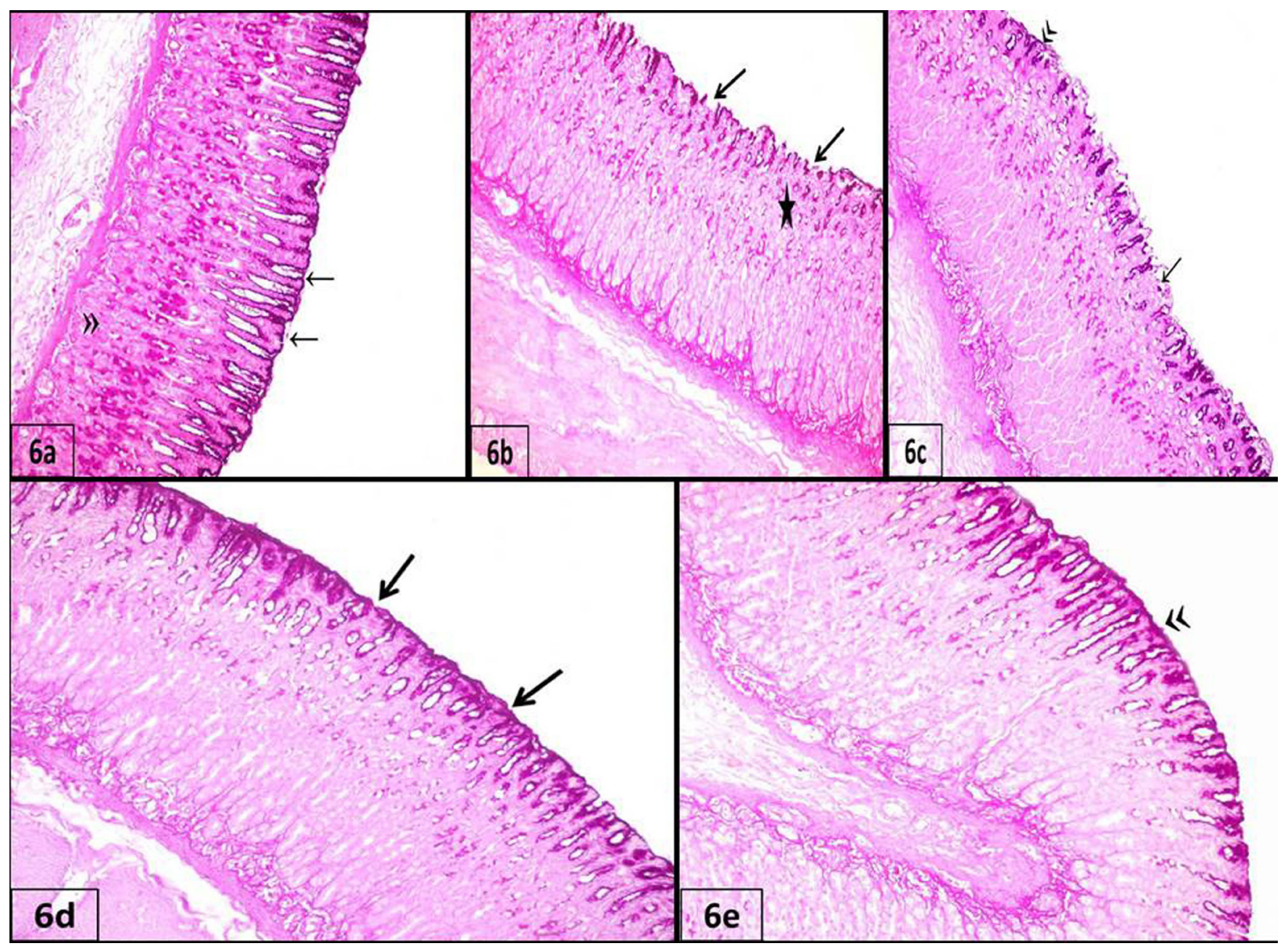

Fig. (6): A photomicrograph of PAS stained fundic gastric mucosa of different studied groups: (6a control group) showing strong PAS positive material $(\rightarrow)$ covering the surface of gastric mucosa and extending downwards to fill the gastric pits \& isthmus of the glands and weak reaction at the base of the glands (»). ( $6 \mathrm{~b}$ subgroup IIA) exhibiting localized decrease of PAS reaction of surface mucous coat $(\rightarrow)$ and in the isthmus and neck of the glands $(*)$. (6c subgroup IIB) displaying marked decrease of PAS reaction of the surface mucous coat (») with areas of focal loss $(\rightarrow)$. (6d subgroup IVA) showing PAS positive reaction covering the mucosal surface $(\rightarrow$ ) and extending to line the gastric pits. (6e subgroup IVB) depicting PAS positive material covering the surface columnar cells of (») extending to fill the pits (PAS X 200) 


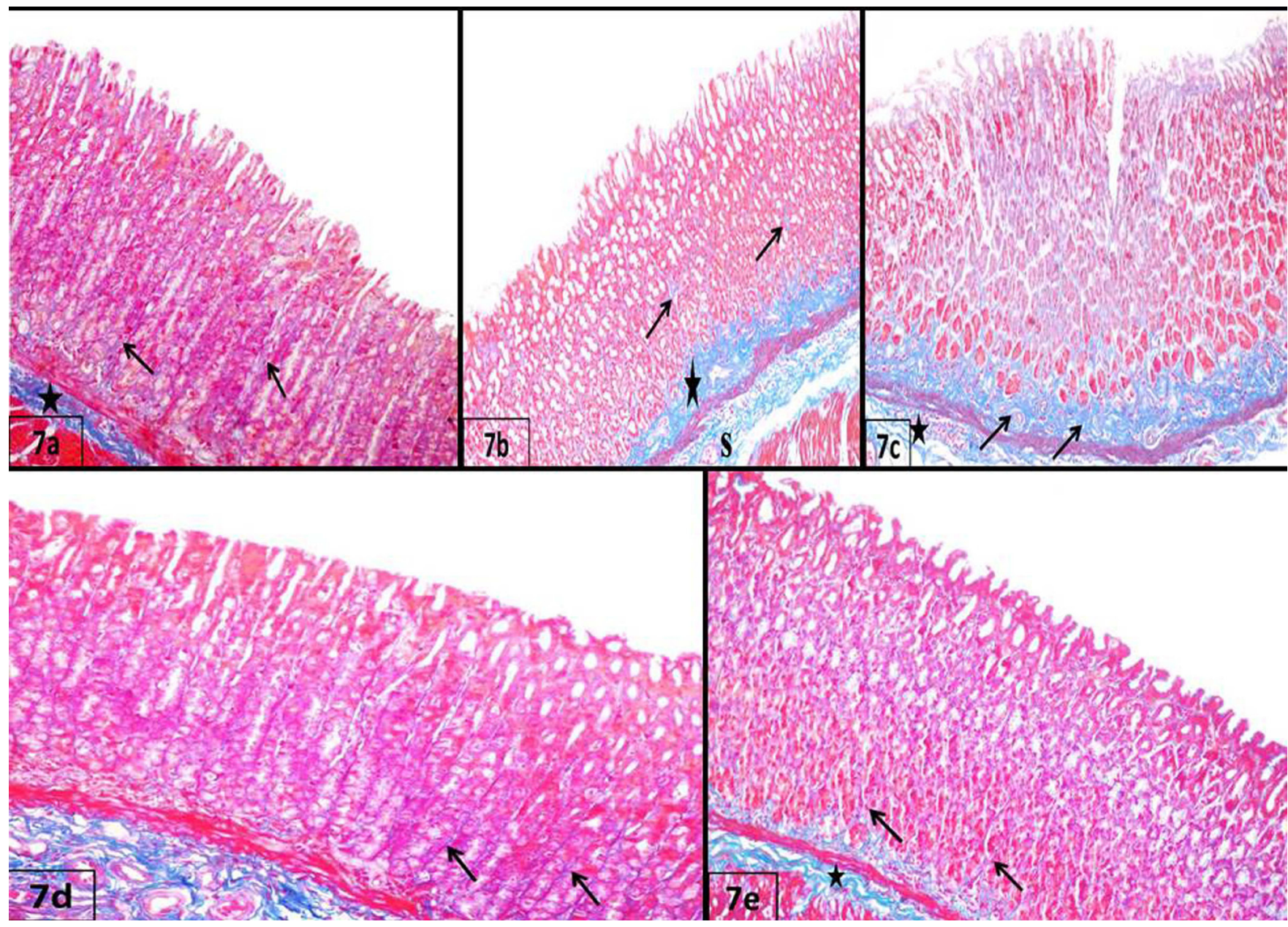

Fig. (7): A photomicrograph of Mallory trichrome stained fundic gastric mucosa of different studied groups; (7a control group) showing few amount of collagen fibers between the fundic glands $(\rightarrow)$ and mild in the submucosa $(*)$. (7b subgroup IIA) showing moderate increase in collagen fibers between the fundic glands $(\rightarrow)$, in the lamina propria especially at the base of the glands $(*)$ and the submucosa (S). (7c subgroup IIB) showing marked deposition of collagen fibers in between fundic glands, in the lamina propria $(\rightarrow)$ and in the submucosa $(*)$. (7d subgroup IVA) showing few collagen fibers between fundic glands $(\rightarrow)$. (7e subgroup IVB) showing few collagenous fibers between the fundic glands $(\rightarrow)$ but great in the submucosa $(*)$

(Mallory trichrome X 200) 


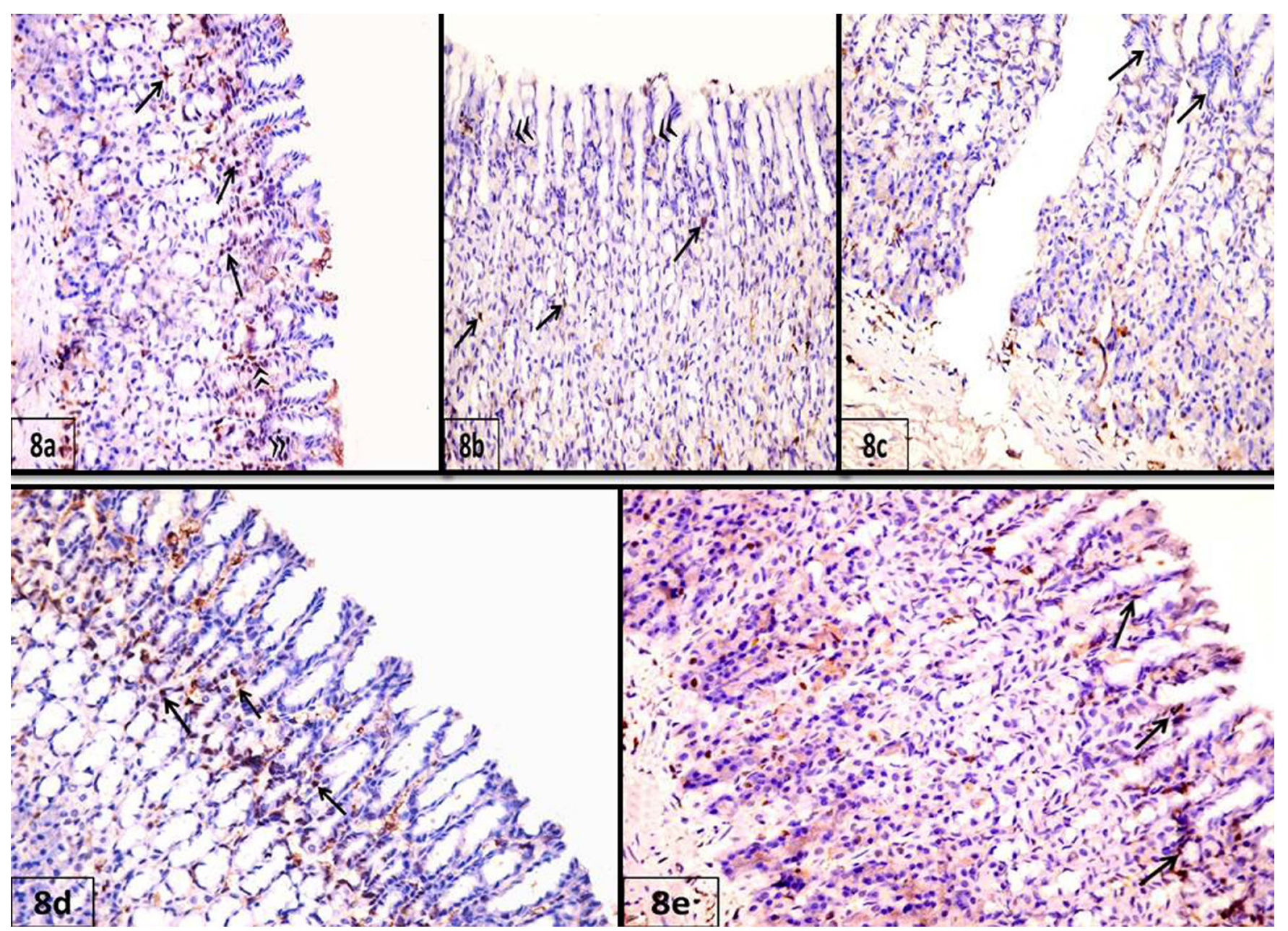

Fig. (8): A photomicrograph of PCNA immunostained fundic gastric mucosa of different studied groups. (8a control group) showing strong positive brown PCNA immunoreactivity in many nuclei of cells lining the isthmus (») \& neck of the gastric glands ( $\rightarrow$ ). (8b subgroup IIA) revealing weak immunoreaction in few nuclei of cells lining the isthmus $(»)$ \& neck of gastric glands of $(\rightarrow)$. (8c subgroup IIB) showing very weak PCNA immunoreactivity in the nuclei of cells lining the neck of gastric glands $(\rightarrow)$. (8d subgroup IVA) showing strong PCNA immunoreactivity in many nuclei of cells lining the isthmus \& neck of gastric glands of $(\rightarrow)$. (8e subgroup IVB), showing moderate PCNA immunoreactivity in the nuclei of cells lining the isthmus of gastric glands $(\rightarrow$ ) ( PCNA immunostaining, with counter stain Haematoxylin $\mathrm{x} 400)$. 


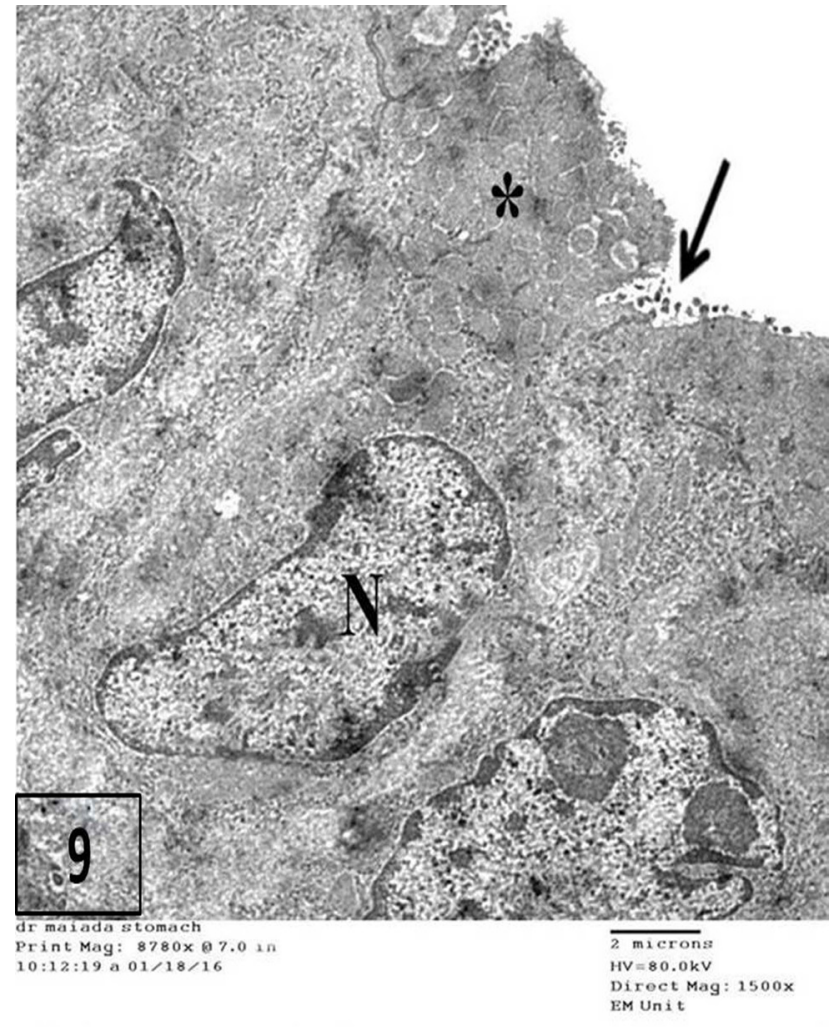

Fig. (9): An electron micrograph of surface columnar cell of the control group appeared tall columnar cell having apical microvilli $(\rightarrow)$, apical mucinogen granules $(*)$ and basal oval nucleus $(\mathrm{N})$ with prominent nucleolus

(Mic. Mag. X 1500)

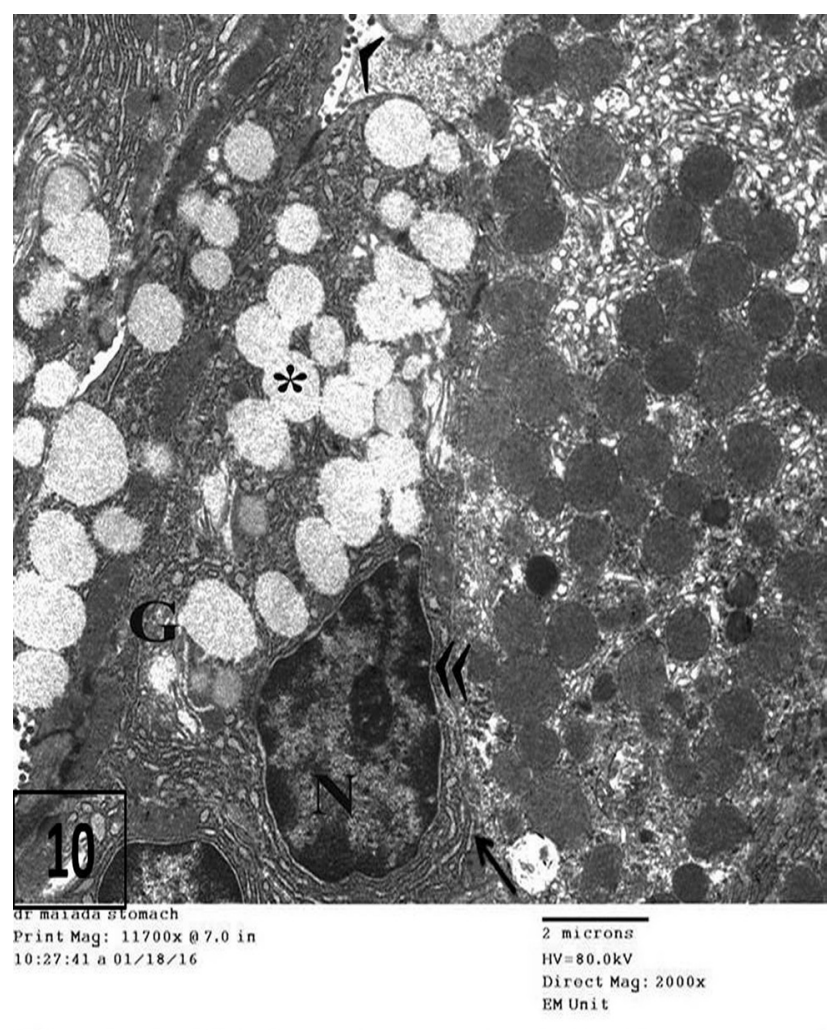

Fig. (10): An electron micrograph of mucous neck cell of the control group showing, apical microvilli ( $)$, apical numerous secretory granules $(*)$, Golgi apparatua $(\mathrm{G})$, basal rER $(\rightarrow)$ and basal nucleus $(\mathrm{N})$ with prominent nucleolus and nuclear pores $(\gg)$ (Mic. Mag. X 2000).

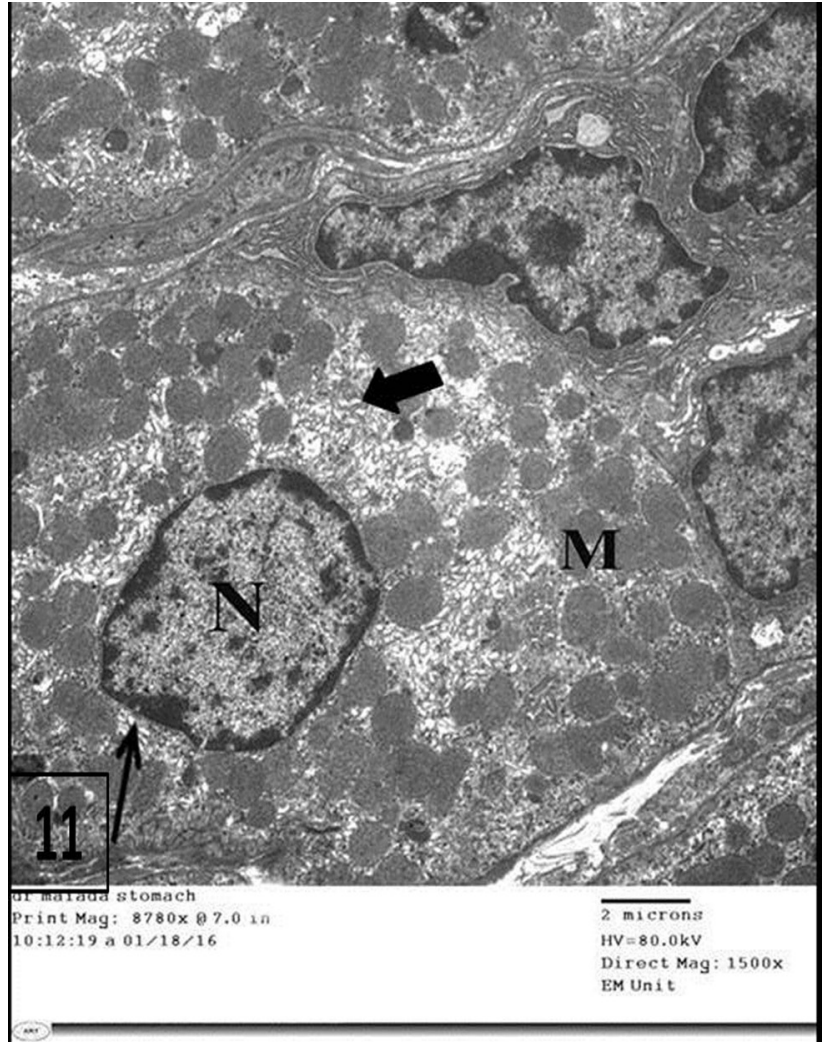

Fig. (11): An electron micrograph of parietal cell of the fundic gastric mucosa of the control group showing, large pyramidal cel having; intracellular canaliculi ( ), numerous mitochondria (M) and central spherical nucleus $(\mathrm{N})$ with prominent nuclear pores $(\rightarrow) \quad$ (Mic. Mag. X 1500)

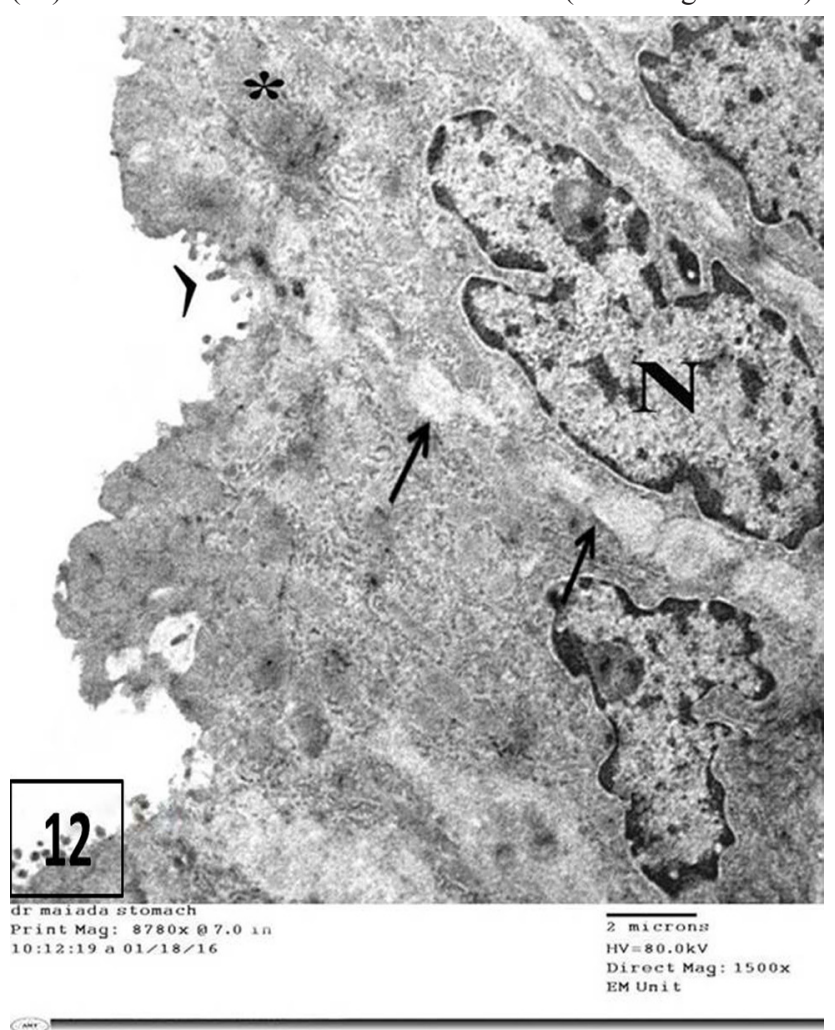

Fig. (12): An electron micrograph of surface columnar cell of subgroup IIA showing sparse apical microvilli (〉), little amount of secretory granules $(*)$, wide intercellular space $(\rightarrow)$ and the nucleus appeared indented (N) and (Mic. Mag. X 1500). 


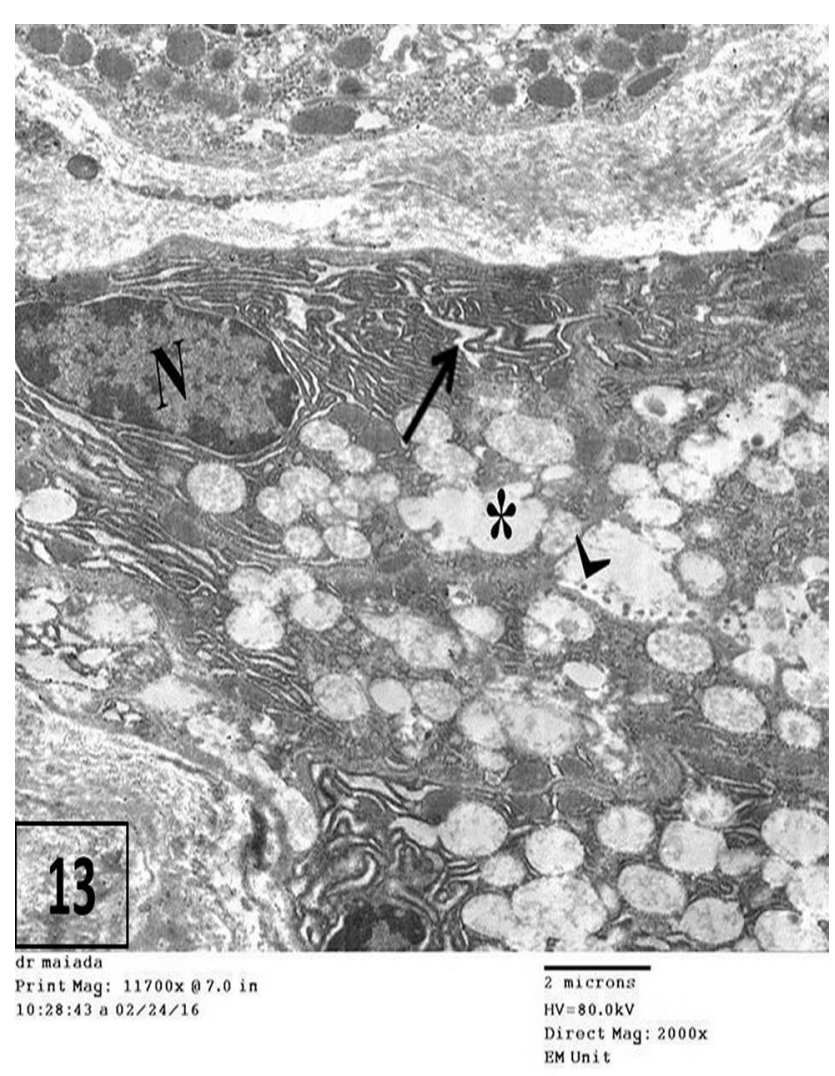

Fig. (13): An electron micrograph of mucous neck cell of subgroup IIA showing few microvilli $(\iota)$, coalescence of secretory granules $(*)$ and dilated rER $(\rightarrow)$

(Mic. Mag. X 2000).

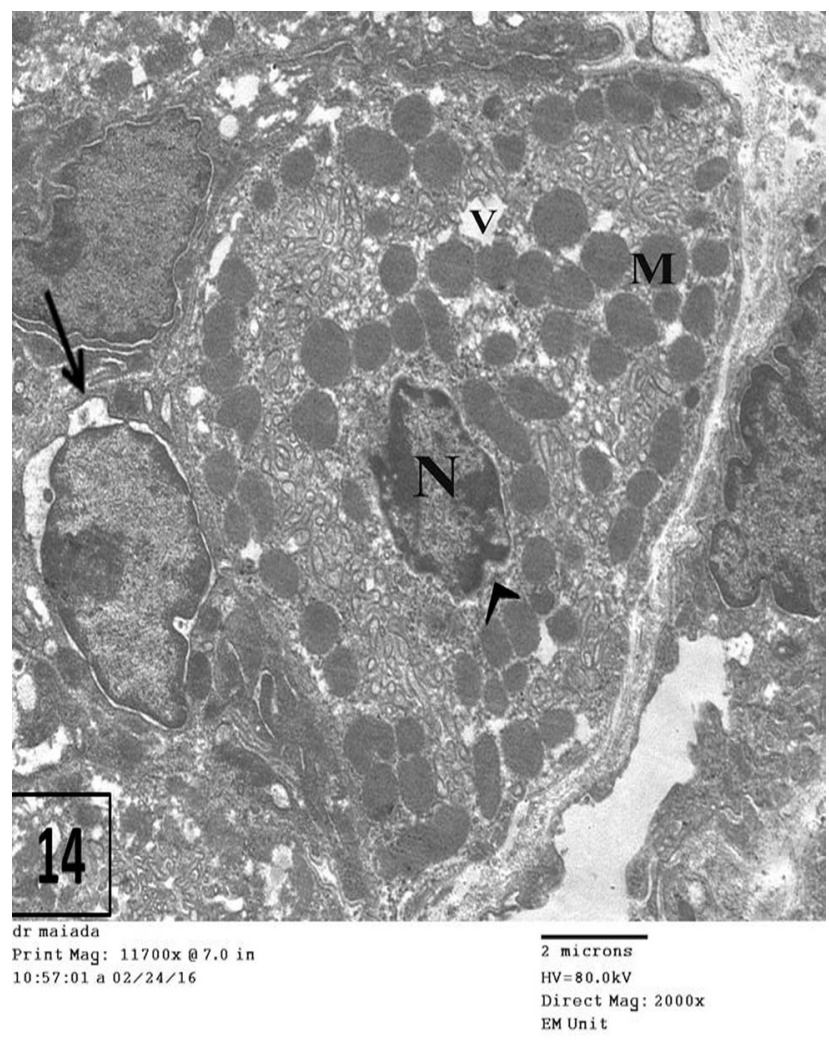

Fig. (14): An electron micrograph of parietal cell of subgroup IIA showing; few cytoplasmic vacuoles (V), normal mitochondria $(\mathrm{M})$, indented shrunken nucleus $(\mathrm{N})(\diamond)$ and dilated perinuclear space $(\rightarrow)$ (Mic. Mag. X 2000).

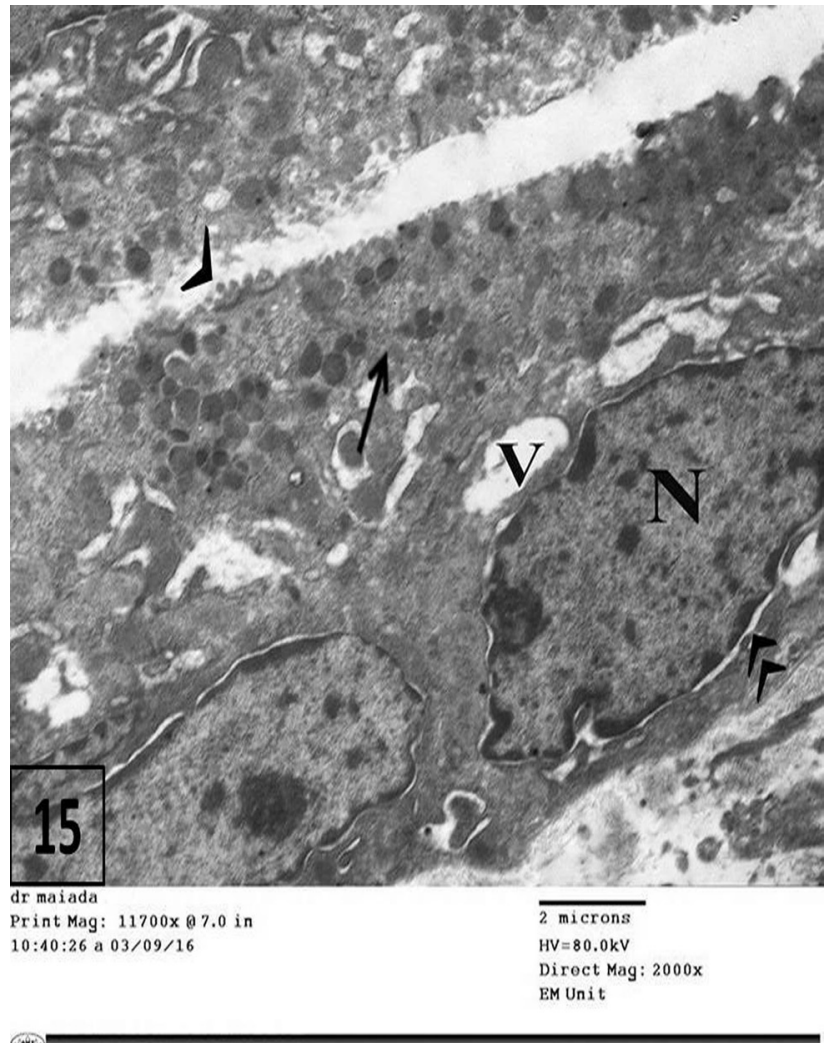

Fig. (15): An electron micrograph of surface columnar cells of subgroup IIB showing few apical microvilli (>), few apical mucinogen granules $(\rightarrow)$, cytoplasmic vacuoles $(\mathrm{V})$, basal indented nuclei $(\mathrm{N})$, nucleolar margination and wide perinuclear spaces $(»)$ (Mic. Mag. X 2000)

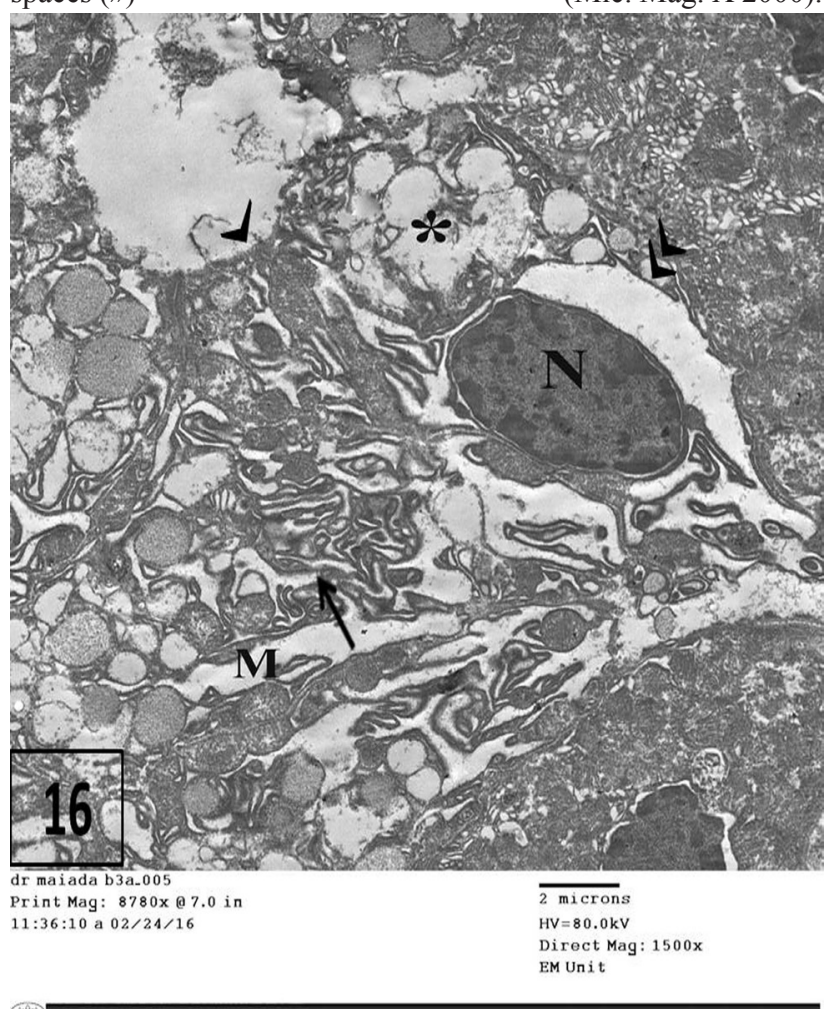

Fig. (16): An electron micrograph of mucous neck cell of subgroup IIB showing, absence of apical microvilli (১), coalescence of secretory granules $(*)$, markedly dilated rER $(\rightarrow)$, normal mitochondria $(\mathrm{M})$ and perinuclear vacuolation $(»)$ (Mic. Mag. X 1500). 


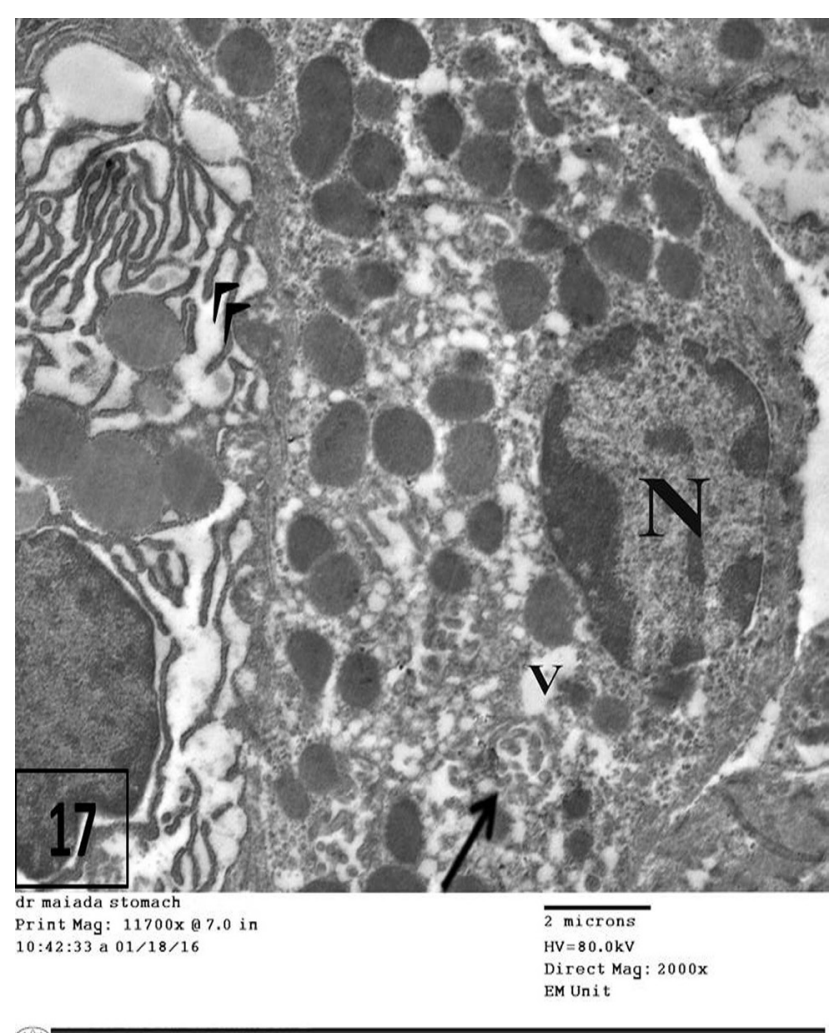

Fig. (17): An electron micrograph of parietal cell of subgroup IIB showing flattening of the cell ( $)$, cytoplasmic vacuoles (V), normal mitochondria $(\mathrm{M})$, dilated intracellular canaliculi $(\rightarrow)$, dilated rER (») and basal nucleus (N) (Mic. Mag. X 2000).

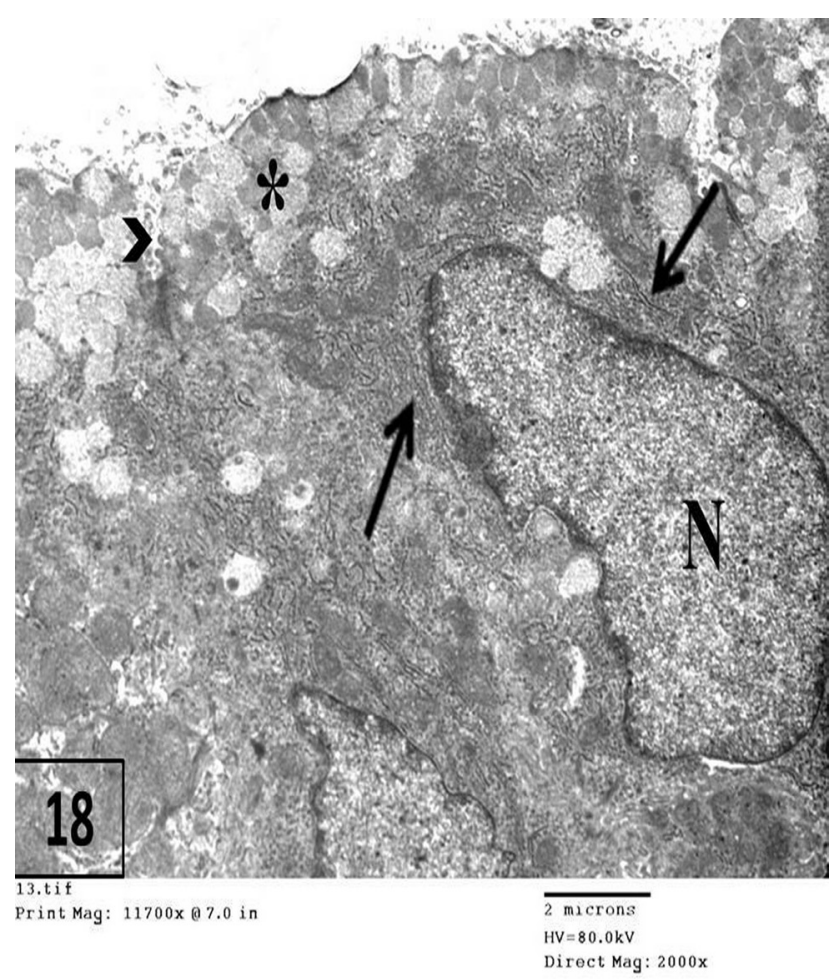

Fig. (18): An electron micrograph of surface mucous cell of the fundic gastric mucosa of subgroup IVA showing, columnar cell having normal apical microvilli within the gastric lumen $(>)$, apical secretory granules $(*)$, basal $\mathrm{rER}(\rightarrow)$ and basal oval nucleus $(\mathrm{N})$ with regular nuclear membrane and extended chromatin

(Mic. Mag. X 2000)

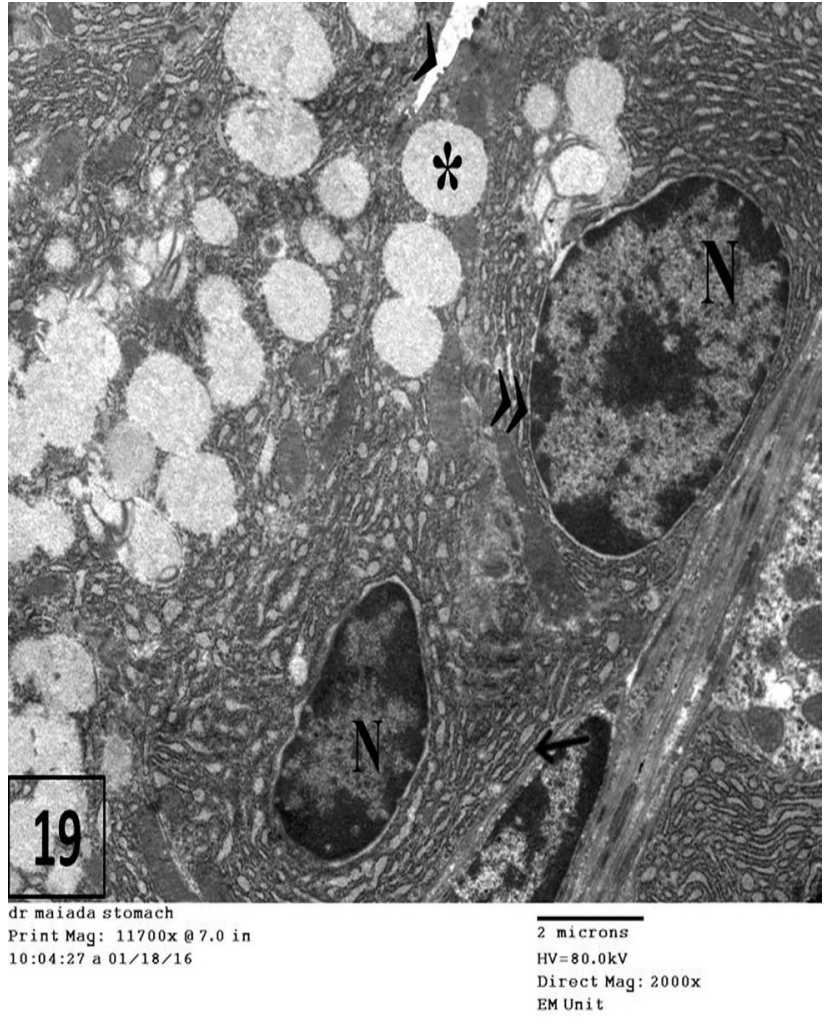

Fig. (19): An electron micrograph of two mucous neck cells of subgroup IVA showing few apical microvilli ( ), presence of apical secretory granules $(*)$, basal rER $(\rightarrow)$ and basal oval nuclei $(\mathrm{N})$ with prominent nucleoli and nuclear pores (»)

(Mic. Mag. X 2000)

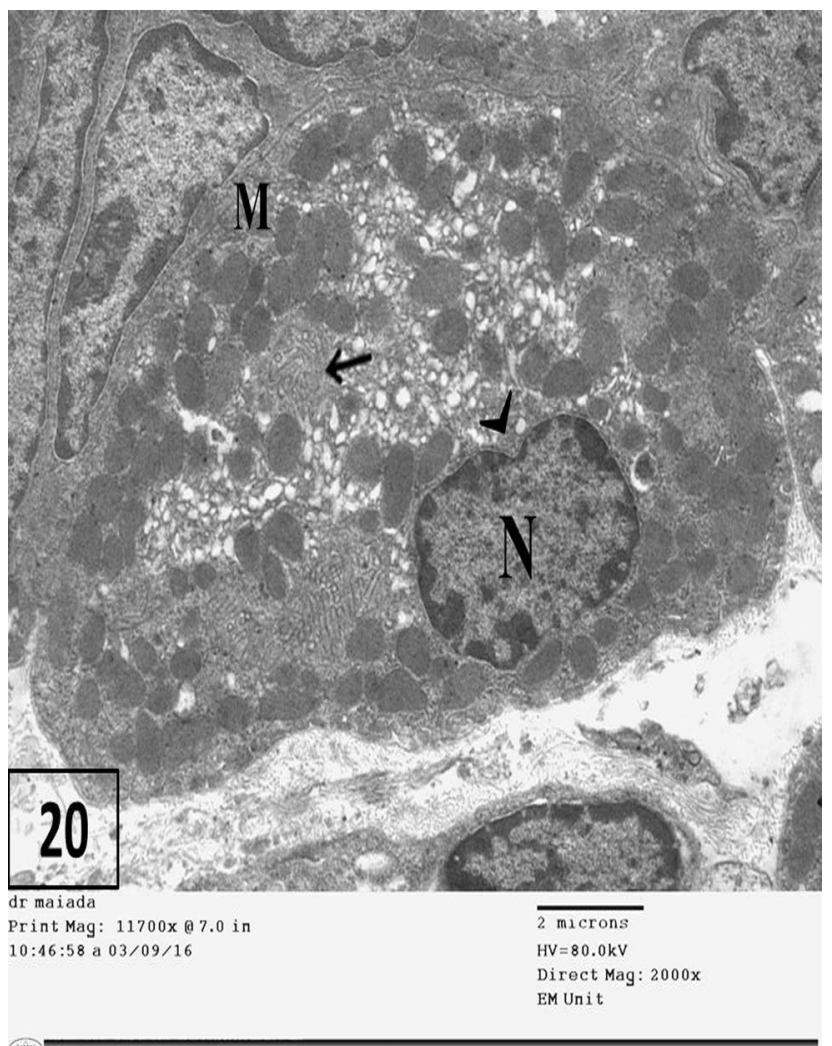

Fig. (20): An electron micrograph of parietal cell of subgroup IVA showing, more or less normal parietal cell having normal intracellular canaliculi (>), numerous mitochondria (M) and slight indentation of the nuclear membrane $(\rightarrow)$ (Mic. Mag. X 2000). 


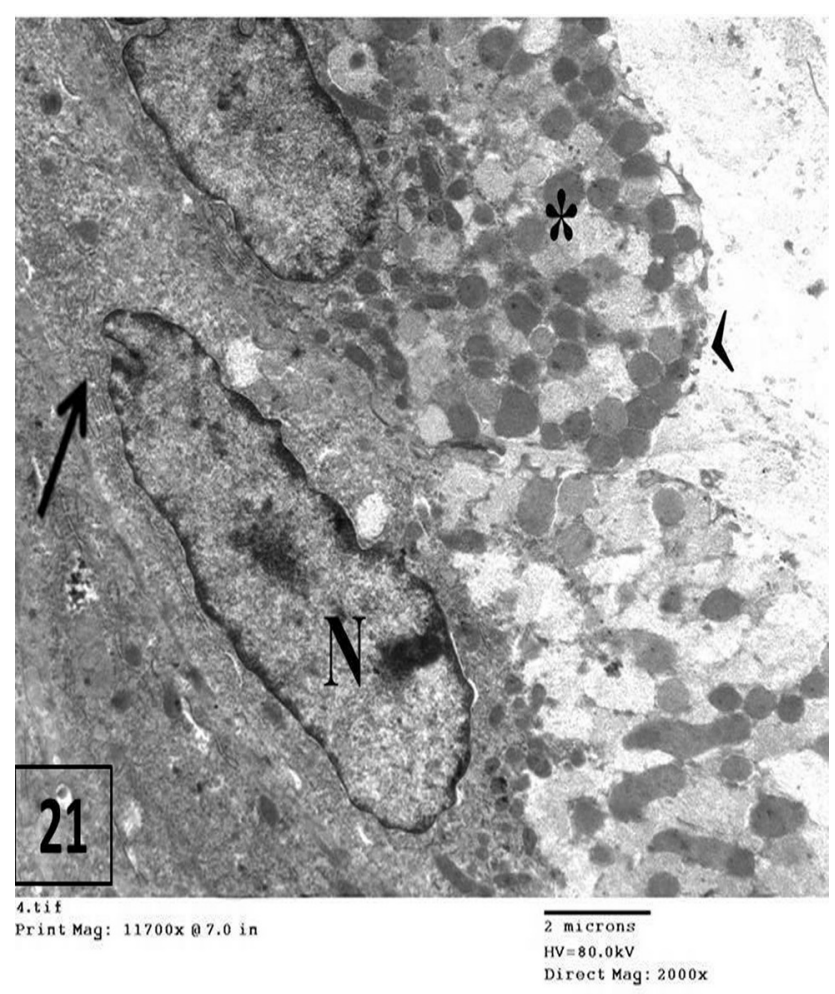

Fig. (21): An electron micrograph of surface columnar cell of subgroup IVB showing, apical microvilli ( $)$, apical numerous secretory granules $(*)$, basal $\mathrm{rER}(\rightarrow)$ and basal oval nucleus $(\mathrm{N})$ with prominent nucleolus (Mic. Mag. X 2000).

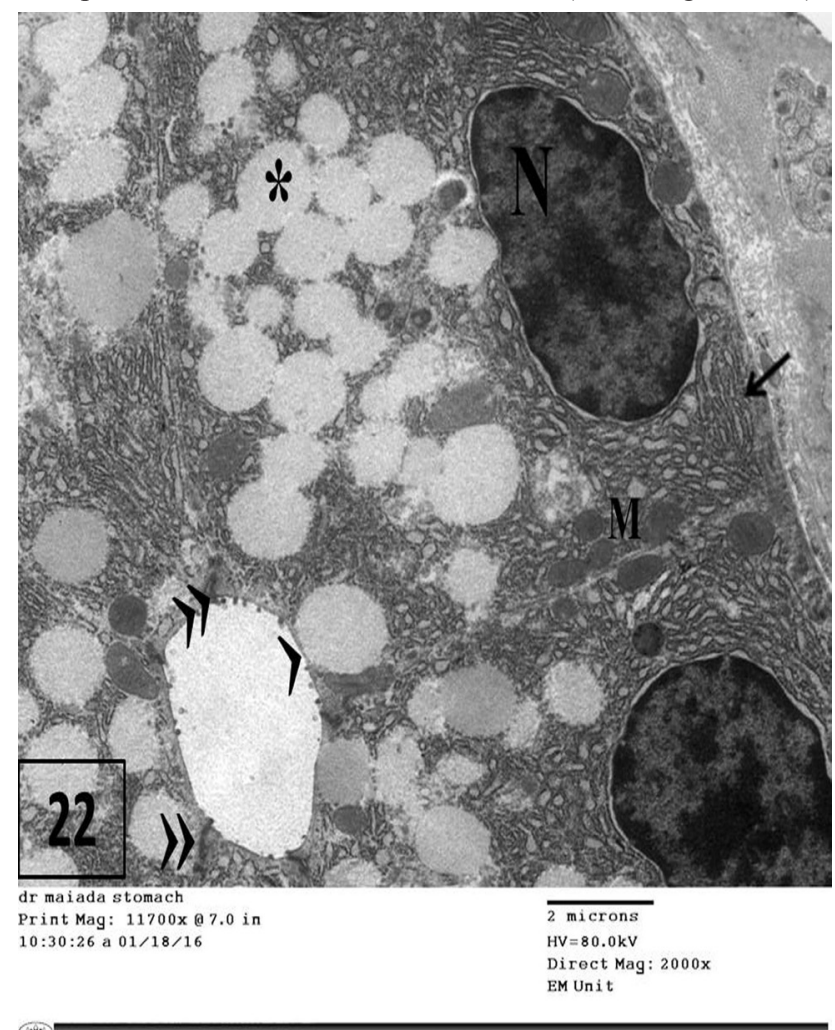

Fig. (22): An electron micrograph of mucous neck cell of subgroup IVB showing, few apical microvilli (〉), normal intercellular junctions \& intercellular spaces (»), coalescence of apical secretory granules $(*)$, basal rER $(\rightarrow)$, mitochondria $(\mathrm{M})$ and basal flattened nucleus $(\mathrm{N})$ with prominent nucleolus and normal chromatin distribution

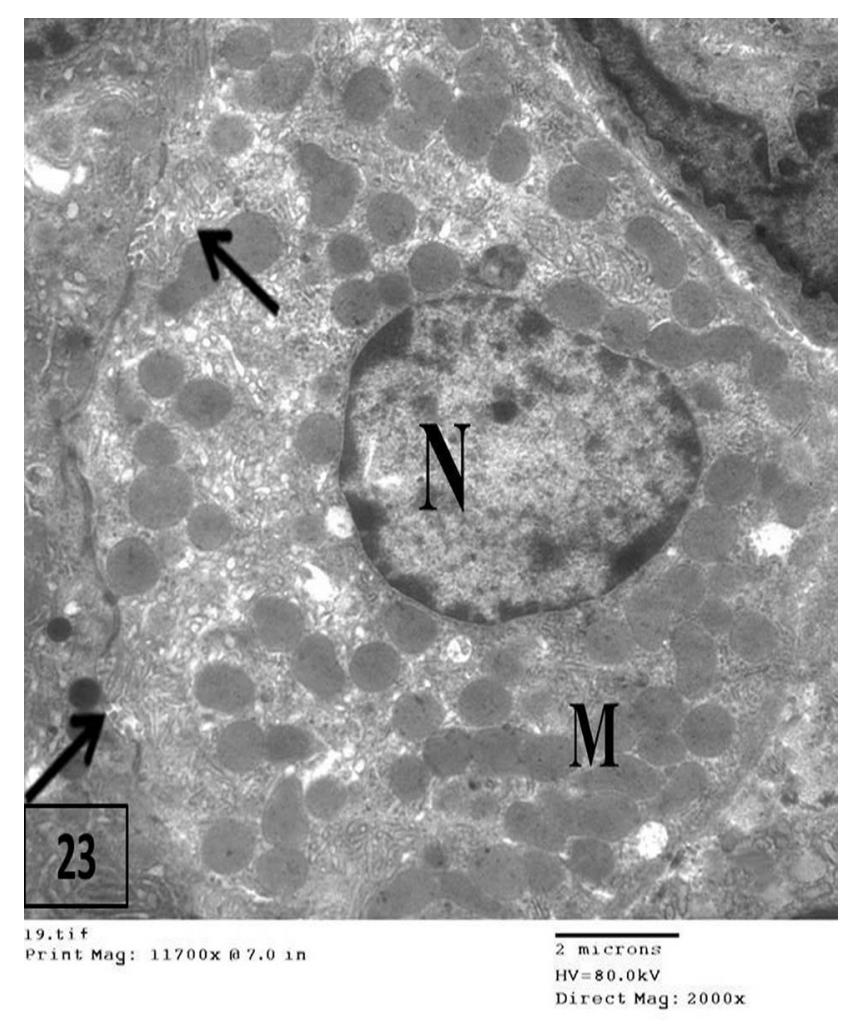

Fig. (23): An electron micrograph of parietal cell of subgroup IVB showing, pyramidal cell with intracellular canaliculi lined with microvilli $(\rightarrow)$, rounded to oval normal mitochondria (M) and nearly central spherical nucleus (N) （Mic. Mag. X 2000).

\section{DISCUSSION}

The present work was designed to investigate the effect of leflunomide on the histological structure of the fundus of the stomach of adult male albino rats and to evaluate the possible ameliorative role of L-arginine. The light microscopic examination of this current study revealed that leflunomide induced focal changes on the fundic gastric mucosa in the form of epithelial discontinuity, erosions, sloughing $\&$ desquamation of surface epithelial cells two weeks after drug administration and aggravated after four weeks causing deep ulceration reaching the muscularis mucosa. These degenerative changes were observed by Duncan \& Grant (2003), Youmba et al., (2012), Vivar \& Van Vollenhoven (2014) and Hagras et al., (2014) and they referred these changes to the affection of tight junction proteins as claudin-1, occluding and zonula occludens-1; resulting in, disruption of cell to cell interaction, inhibition of mitosis and decrease of epithelial integrity give rise to sloughing and desquamation. Moreover, leflunomide inhibits DNA synthesis and cell proliferation resulting in impaired epithelial regeneration (Mossalam \& Yousuf, 2013).

Shortening and widening of gastric pits observed in group II in this work could be attributed to the excess mucus secretion as an attempt by the body to safe 
guard against more damage to the surface coat of the gland (Hagras et al., 2014). In addition, the separated gastric glands could be due to inflammatory cellular infiltration that was formed of different kinds of cells mainly mast cells which release histamine. The latter led to dilatation of blood capillaries, increase their permeability and their filtration in the interstitial spaces and subsequently; edema of interstitial spaces (Chandrasoma \& Taylor, 2008). The inflammatory infiltration might occurred from the imbalance between the gastrotoxic agents and the protective mechanisms of gastric mucosa stimulating release of interleukin-1 and tumor necrosis factor alpha leading to infiltration of gastric mucosa with inflammatory cells (Konturek et al., 2000). Also, it could be due to affection of the integrity of intercellular junction between surface columnar cells as the mucosa became more exposed to the effect of acid and proteolytic enzymes with subsequent bacterial invasion which might be chemotactic for neutrophils, lymphocytes and macrophages (Ribet \& Cossart, 2015).

The vacuolated parietal cells and their darkly stained nuclei were observed with Vassilev et al. (2004) and Hail et al. (2010). They reported that leflunomide promotes apoptotic effect on epithelial cells. These degenerative changes could be explained on the basis of oxidative stress induced by leflunomide especially on long duration as it promotes mitochondrial damage and release of cytochrome-c into cytosol. (Mcinnes et al., 2011).

In this research, there was reduction of PAS reaction of the surface mucous coat and in the isthmus $\&$ neck of the glands with appearance of areas of focal loss of PAS over the sites of erosions and ulceration. These results could be due to depletion of PAS stained mucous secretory granules of surface columnar cells as confirmed by electron microscopic findings. Hamilton et al. (1999) also who reported that leflunomide via its active metabolite A771726 decreases the accumulation of prostaglandins through inhibiting the cyclooxygenase (COX) enzymes and so the mucus secretion and the PAS reaction decreased.

The increase in the deposition of collagen fibers observed between fundic glands in the lamina propria and in the submucosa after two weeks and became more evident after 4 weeks of leflunomide administration could be explained by the ability of A771726 to induce pulmonary fibrosis through activation of myofibroblast which started deposition of collagen and extracellular matrix components (Namba et al., 2010).

The immunohistochemical results of this study revealed statistically highly significant decrease in the mean number of PCNA positive cells in the isthmus and neck of gastric glands after two and four weeks of leflunomide intake compared with the control group. This finding might be due to the ability of A771726 to inhibit the proliferation of cells stimulated by platelets derived growth factor (PDGF) through suppressing tyrosine phosphorylation of PDGF receptors, so leflunomide has anti-proliferative and anti-angiogenic effect. It also inhibits the proliferation of stem cells in the isthmus of gastric glands as an attempt of healing because the gastric stem cells are under the control of PDGF (Kawai \& Rokutan, 1995 and Nguyen et al., 2007).

It was observed during this research by TEM loss of apical microvilli of mucous cells, cytoplasmic vacuoles, dilated rough endoplasmic reticulum and presence of perinuclear space in most cells of the gastric mucosa in group II. These findings could be attributed to lipid peroxidation of biological membranes which increases its permeability to ions causing disruption of membrane structure. Moreover, Moriel et al., (2000) referred it to the blunt effect of leflunomide on the mitochondrial dihydroorotate dehydrogenase, leading to formation of high conductance channel in the mitochondrial membrane, loss of membrane potential, ATP depletion and activation of phospholipase enzyme leading to breakdown of phospholipids and their depletion from the cell membrane. Dilatation of rER were referred by Fawcett \& Jensh, (2002) as a trial of the cell to increase its surface area which is a compensatory mechanism bearing the function of severely damaged cells. Other researchers added that deleterious agents might interfere with ATP-dependent $\mathrm{Na}+/ \mathrm{K}+$ pump by increasing the permeability of cell membrane to sodium, thereby exceeding the capacity of the pump to extrude sodium, or damaging the pump itself. Accumulation of sodium in the cell leads to increase in water content and cell swelling, a condition called hydropic degeneration (Rubin \& Strayer, 2012).

Coalescence of mucous secretory granules observed in mucous neck cells and apparent decrease in the amount of secretory granules were also observed in surface columnar cells two and four weeks after leflunomide treatment. The coalescence of secretory granules was attributed to the increase in the mucus secreted by gastric mucous cells due to accelerated exocytosis as a response to cell membrane disruption. This disruption-induced exocytosis acts as protective mechanism depends on entrance of extracellular $\mathrm{Ca}++$ and liberating mucus at sites of injury (Miyake et al., 2006). The apparent decrease in secretory granules was also observed by Caselli et al. (1995) and Crivellato et al. (2002).

Dilatation of intracellular canaliculi of parietal cell might be due to the stimulation of the cell by histamine leading to re-arrangement of cytoskeleton and recruitment of $\left(\mathrm{H}^{+} / \mathrm{K}^{+}\right.$-ATPase $)$rich tubulo- 
vesicles to the apical membrane expanding the intracellular canaliculi with loss of luminal microvilli (Ogata \& Yamasaki, 2000). This dilatation occurs in the active phase of secretion. The initiation of these morphological changes is induced by the cytoskeletal actin and phosphorylated ezrin which were essential for fusion of membranes of tubulo-vesicular system with the canaliculi causing its expansion and activation of $\mathrm{H}^{+} / \mathrm{K}^{+}$-ATPase with subsequent gastric acid secretion (Wakamatsu et al., 2005).

Nuclear changes in the form of nuclear membrane irregularities, abnormal distribution of chromatin and even shrinked hyperchromatic nuclei with nucleolar margination might be a step towards cell apoptosis. These results were in harmony with Shi et al., (2011) who suggested that leflunomide and its active metabolite A771726 have cytotoxic effect on cytochrome P450 enzymes leading to its inhibition. Accordingly, Mossalam \& Yousuf (2013) attributed theses ultrastructure findings to over-expression of Bcl-2 immunolocalization in both hepatocytes and endothelial sinusoids.

In the present study, when L-arginine was taken with leflunomide concomitantly either for two or four weeks the histological changes occurred in the cells lining the fundic gastric mucosa became improved and appeared more or less near normal architecture. The gastric glands were lined with nearly normal cells. The mononuclear inflammatory cells and congested blood vessels in the lamina propria were markedly reduced.

Many experimental studies revealed that L-arginine has beneficial effect on the healing of gastric ulcer in rats and referred it to the release of nitric oxide which plays an important role in gastric mucosal defense mechanisms though maintaining mucosal integrity, controlling gastric motility and secretion, enhancing mucosal blood flow and wound healing (Elliot et al., 1995, Khattab et al., 2001, Nishio et al., 2006, Ajiboye et al., 2014 and Usman et al., 2014). NO has the ability to activate COX-1 and COX-2 enzymes responsible for gastric defense via the action of prostaglandins $\mathrm{E}$ and F2 $\alpha$. The latter stimulate epithelial cells to release more bicarbonate and mucus, inhibit gastric secretion, increase mucosal blood flow, reduce the release of a number of the inflammatory mediators and accelerate ulcer healing (Wallace, 2008).

The released NO improves microcirculation around the ulcer by enhancing angiogenesis through stimulating vascular endothelial growth factor (VEGF) synthesis. These new blood vessels would deliver more blood and transport oxygen and nutrients to the site of inflammation enhancing healing, as well as it delivers bicarbonates to the surface epithelium to neutralize the acid secretion (Chatterjee et al., 2012 and Zandifar et al., 2012). The apparent decrease of mononuclear cellular infiltration in the current work could be referred to the anti-inflammatory activity of NO (Lefer et al., 1999). In addition, L-arginine itself has an antioxidant activity by which it gets rid of superoxide anions and hydrogen peroxide (Khattab et al., 2001 \& Lundberg et al., 2008).

Subgroup IVA revealed non-significant change in mean optical density of PAS reaction covering the gastric mucosa when compared to control. This was in parallel with Ito et al. (2008) who mentioned that NO has gastro-protective mechanism by increasing the thickness of gastric mucus gel through stimulating the secretion of mucus by gastric epithelial cells regaining the thick mucus coat. Few collagen fibers were observed in-between the gastric glands and in the submucosa by Mallory trichrome stain and this was attributed to the anti-inflammatory effect of NO and L-arginine. This result was in agreement with Svegliati-Baroni et al. (2001) who reported that NO attenuate the proliferation of hepatic stellate cells induced by reactive oxygen species leading to decrease the amount of collagen deposition.

Subgroup IVA also showed significant increase in number of PCNA immunostained cells and highly significant increase in cells in subgroup IVB after four weeks. This might be attributed by Wong \& Fiscus (2011) to nitric oxide which in low concentration induces cell proliferation.

\section{CONCLUSION}

Based on the current study and from all previously mentioned results; it was found that leflunomide had deleterious effects on the fundic gastric mucosa and L-arginine was used to protect against this damage as a precursor of nitric oxide which plays an important roles in the stomach.

\section{CONFLICT OF INTEREST}

There is no conflict of interest to declare.

\section{REFERENCES}

1. Ajiboye, K.I.; Oluwole, F.S. and Ajiboye, O.F.: Effects of L-Arginine supplementation on indomethacininduced gastric ulceration in rats. Journal of Research and Development. 2014; 8-16.

2. Bancroft M. and Gamble J.D. Theory and Practice of Histological Techniques. 6th edition. Philadelphia. Churchill Livingstone. 2008; 121.

3. Bozzola J.J. and Russell L.D. Electron Microscopy: Principles and Techniques for Biologists. $2^{\text {nd }}$ edition. Jones \& Bartlett Pub. Toronto, London. (1999): P: 16. 
4. Brzozowski, T.; Konturek, S.J.; Sliwowski, Z.; Drozdowicz, D.; Zaczek, M. and Kedra, D.: Role of L-Arginine, a substrate for nitric oxide-synthase in gastroprotection and ulcer hearing. J. Gastroenterol. 1997; 32: 442-452.

5. Buettner, R.; Morales, C.; Perret, N.; Palmer, J.; Krishnan, A.; Rosenzweig, M. and Rosen, S.T.: Repurposing Leflunomide for Multiple Myeloma Treatment. BLOOD. American Society of Haematology. 2016; 128-5667.

6. Caselli, M.; Lacorte, R.; Decarlo, L.; Aleotti, A.; Trevisani, L.; Ruina, M.; Trotta, F. and Alvisi, V.: Histological findings in gastric mucosa in patients treated with non-steroidal anti-inflammatory drugs. J. Clin. Pathol. 1995; 48(6): 553-555.

7. Cesar A.C.G., De Frietas C.M., Cury P.M. and Caetano A.: Genetic alterations in benign lesions: chronic gastritis and gastric ulcer. J. World Gastroenterol. 2006; 12: 625-629.

8. Chatterjee,A.; Chatterjee, S.; Biswas, A.; Bhattacharya, S.; Chattopadhyay, S. and Bandyopadhyyay, S. K.: Gallic Acid Enriched fraction of Phyllanthus emblica Potentiates Indomethacin-Induced Gastric Ulcer Healing via e-NOS- Dependent Pathway. EvidenceBased Complementary and Alternative Medicine. 2012; 13-18.

9. Chandrasoma, P. and Taylor, C.R.P: Concise Pathology" Part A. General Pathology". The host response to injury. "The Acute Inflammatory Response". 3rdedition. New York N.Y.: McGraw-Hill. 2008: 11-15.

10. Crivellato, E.; Ribatti, D.; Mallardi, F. and Beltrami, C.A.: Granule changes of human and murine endocrine cells in the gastrointestinal epithelia are characteristic of piecemeal degranulation. J. Anat. Rec. 2002; 268(4): 353-359.

11. Culling C.F., Allison R.T. and Barr W.T.: Cellular pathology techniques. 4thedition. Butterworth, London, Boston, Toronto. 1985; 25-28.

12. Cynober, L: Can arginine and omithine support gut functions? Gut. 1994; 1: 42-45.

13. Davies, H.T. and Crombie, L.K.: what are confidence intervals and p-values?. $2^{\text {nd }}$ edition. Hayward Group Ltd. 2009; 1-6.

14. Derosa, F.; Keefer, LK.; Hrabie, JA.: Nitric oxide reacts with methoxide. J. Org. Chem. 2008; 73: 11391142 .
15. Duncan, M. and Grant, G.: Oral and intestinal mucositis- causes and possible treatments. Aliment Pharmacol Ther. 2003; 18: 853-874.

16. Elliott, S.N.; Mcknight, W.; Cirino, G. and Wallace, J.L.: A nitric oxide-releasing non-steroidal antiinflammatory drug accelerates gastric ulcer healing in rats. Gastroenterology.1995 ;109: 524-530.

17. Fawcett, D.W. and Jensh, R.P.: Bloom and Fawcett. Concise Histology. 2nd edition. Chapman and Hall. New York, London, Toronto. 2002: 195-200.

18. Hagras, G.M.; Mansour, M.A.; Ghoneim, N.S.; ElDamhogy, R.A.W. and Abdel Aziz, S.A.M.: Effect of anti-rheumatic drug leflunomide (Avara) on the pyloric region of the stomach of adult male albino rats and the possible effect of rantidine (histological and histochemical study). Journal of American Science. 2014; 10(11): 86-100.

19. Hail, N. Jr.; Chen, P. and Bushman, L.R.: Teriflunomide (leflunomide) Promotes Cytostatic, Antioxidant and Apoptotic Effects in Transformed Prostate Epithelial Cells: Evidence Supporting a Role for Teriflunomide in Prostate Cancer Chemoprevention. Neoplasia. 2010; 12(6): 464-475.

20. Hamilton, L.C.; Vajnovic, I and Warner, D.T.: A771726, the active metabolite of leflunomide, directly inhibits the activity of cyclooxygenase- 2 in vitro and in vivo in a substrate-sensitive manner. $\mathrm{Br} \mathrm{J}$ Pharmacol. 1999; 127(7): 1589-1596.

21. Ito, Y.; Okuda, S.; Ohkawa, F.; Kato, S.; Mitsufuji, S. and Yoshikawa, T. : Dual role of nitric oxide in gastric hypersecretion in the distended stomach: inhibition of acid secretion and stimulation of pepsinogen secretion. J. Life Sci. 2008; 83: 886-892.

22. Kandeel, S.K.E.; Eldeep, A.A.; El Bakary, N.A.R., Abo Hassan N.F.E. and Sarhan, N.I.: Some histological studies of the possible protective effect of l-arginine on ethylene glycol induced damage in gastric mucosa in adult male albino rat. Turk. J. Biol. 2013; 37: 342349 .

23. Karthikeyan M, Arunakaran $\mathrm{J}$ and Balasubramanian K.: The effect of prolactin and corticosteroid on insulin binding to rat leydig cells. Reproductive Biology 2009; 9(2):189-194.

24. Khattab, M.M.; Gad, M.Z. and Abdalla, D.: Protective role of nitric oxide in indomethacin-induced gastric ulceration by mechanism independent of gastric acid secretion. Pharmacological research. 2001; 43(5): 463-467. 
25. Kawai, K. and Rokutan, K.: Kinetics of gastric epithelial cells in duodenal ulcer local environmental factors controlling the proliferation and differentiation of gastric epithelial cells. J. Gatroenterol. 1995; 3: $428-436$

26. Kiernan J.A. Histological and Histochemical Methods: Theory and Practice. 4thedition. Bloxham. UK: Scion 2008: 274- 306.

27. Konturek, P.C.H.; Duda, A. and Brzozowski, T.: Activation of genes for superoxide dismutase, interleukin-1, tumor necrosis factor- $\alpha$ and intercellular adhesion molecule-1 during healing of ischemiareperfusion gastric injury. J. Sc. and. Gastroenterol. 2000; 35: 452-463.

28. Kossi, J.; Elenius, K.; Niinikoski, J.; Peltonen, J. and Latto, M.: overview of wound healing. J. Ann Chir. Gynacol. 2001; 90(215): 15-18.

29. Lefer, D. J. et al.: Leukocyte-endothelial cell interactions in nitric oxide synthase-deficient mice. Am. J. Physiol. 1999; 276: 1943-1950.

30. Lundberg, I.O.; Weitzberg, E. and Gladwin, M.T.: The nitrate-nitrite-nitric oxide pathway in physiology and therapeutics. Nat. Rev. Drug Discov. 2008; 7: 156167.

31. Mcinnes, IB.; Schett, G.N. and Engl, J.: The pathogenesis of rheumatoid arthritis. Med. 2011; 365(23): 2205-2219.

32. Miyake, K.; Tanaka, T. and McNeil, P.L.: Disruptioninduced mucus secretion. Repair and Protection. J. PLOS. Biol. 2006; 4(9): 276-282.

33. Moriel, P.; Plavnik, F.L.; Zanella, M.T.; Bertolami, M.C. and Abdalla, D.SP.: Lipid peroxidation and antioxidants in hyperlipidemia and hypertension. Biol. Res. 2000; 33(2): 716-760.

34. Morita, M; Hayashi, T; Ochiai, M; Maeda, M; Yamaguchi, T; Ina, K. and Kuzuy, M.: Oral supplementation with a combination of L-citrulline and L-arginine rapidly increases plasma L-arginine concentration and enhances NO bioavailability. Biochemical and Biophysical Research Communications. 2014; 454(1): 53-57.

35. Mossalam, H.H and Yousuf, Y.A.: Hepatotoxic Potential of Leflunomide Drug in Adult Male Albino Rats. AAMJ. 2013; 11(2): 284-309.

36. Namba, T.; Tanaka, K.I.; Ito, Y.; Hoshino, T.; Matoyama, M.; Yamakawa, N.; Isohama, Y.; Azuma, A. and Mizushima, T. Induction of EMT-like phenotypes by an active metabolite of leflunomide and its contribution to pulmonary fibrosis. Cell Death Differ. 2010; 17(12): 1882-1895.

37. Nehru, C.; Bhalla, P. and Garg, A.: Further evidence of centrophenoxine mediated protection in aluminum exposed rats by biochemical and light microscopy analysis. J. Food Chem. Toxicol 2007; 45(12): 24992505.

38. Nguyen, T.; Chai, J.; Li, A.; Akahoshi, T.; Tanigawa, T. and Tarnawski, A.S.: Novel Roles of Local Insulin-Like Growth Factor-1 Activation in Gastric Ulcer Healing. Promotes Actin Polymerization, Cell Proliferation, Re-Epithelialization, and Induces Cyclooxygenase-2 in a Phosphatidylinositol 3-Kinase Dependent Manner. Am J Pathol. 2007; 170(4): 12191228.

39. Nishio, H.; Hayashi, Y.; Terashima, S. and Takeushi, $\mathrm{K}$.: Role of endogenous nitric oxide in mucosal defense of inflamed rat stomach following iodoacitamide treatment. Life Sci. 2006; 79: 1523-1530.

40. Ogata, T. and Yamasaki, Y.: Morphological studies on the translocation of tubulovesicular system toward the intracellular canaliculus during stimulation of the gastric parietal cell. J. Mic. Res. Tech. 2000; 48: 282 292.

41. Ribet, D. and Cossart, P.: How bacterial pathogens colonize their hosts and invade deeper tissue. Microbes and Infection. 2015; 17(3): 173-183

42. Rossi, S.E.d.; Australian Medicines Handbook: Adelaide: The Australian Medicines Handbook Unit Trus. 2013; 221-224.

43. Rubin, R. and Strayer, D.S.: Rubin's Pathology: Clinicopathologic Foundations of Medicine. 6thedition. Lippincott Williams \& Wilkins. Philadelphia. 2012: 14-15.

44. Sanchez-Fidalgo, S.; Martine-Lacave, I.; Illanes, M.; Bruseghini, L.; Esteras, A. and Motillva, V.: administration of L-arginine reduces the delay of the healing process caused by ibuprofen. Implication of COX and growth factors expression. J. Histol. Histopathol.2005; 20: 437-447.

45. Sharma R. and Gandhi E. Localization of interleukin-2 in goat ovary. IOSR Journal of Pharmacy. 2012; 2:711.

46. Shi, Q. Yang, X. Greenhaw, J. and Salminen, W: Hepatic Cytochrome P450s Attenuate the Cytotoxicity Induced by Leflunomide and Its Active Metabolite A77 1726 in Primary Cultured Rat Hepatocytes. Toxicological Sciences. 2011; 122(2): 579-586 
47. Bancroft JD and Layton C, Connective and mesenchymal tissues with their stains, Ch11 in Suvarna S.K., Layton C. and Bancroft J.D.(Eds), Bancroft's theory and practice of histological techniques. 7th edition. Elsevier Churchill Livingstone. 2013: 117 124.

48. Svegliati-Baroni, G. Saccomanno, S. Van Goor, H. Jansen, P. Benedetti, A. and Moshage, H.: Involvement of reactive oxygen species and nitric oxide radicals in activation and proliferation of rat hepatic stellate cells. 2001; 21(1): 1-12.

49. Tousson, E.; Ali, E.M.M.; Moustafa, A.H.A.; Moselhey, S.S. and El-Said, K.S.: Proliferating Cell Nuclear Antigen as A Biomarker for Thioacetamide Induced Hepatotoxicity of Rat Liver. American Journal of Zoological Research. 2014; 2(3): 51-54.

50. Usman, D.; Sunday, O.F. and Gabriel, A.T.: Effects of L-Arginine and 1- citrulline on indomethacin- induced gastric ulceration and gastric $\mathrm{pH}$ in male albino rats. European Journal of Medical Plants. 2014; 4(6): 623640.

51. Vassilev, A.; Zheng, Y.; Grigoriants, O.O.; Qazi, S. and Uckun, F.M.: Activation of caspases in human t-lineage leukemia cell treated with analogs of leflunomide metabolite. Eur J Cancer. 2004; 2: 70-74.

52. Vivar, N. and Van Vollenhoven, R.F.: Advances in the treatment of rheumatoid arthritis. F100Prime Reports. 2014; 6: 31-35.
53. Wakamatsu, D.; Tsuyama, S.; Maezono, R.; Kato, K.; Ogata, S.; Takao, S.; Natsugoe, S.; Aikoe, T. and Murata, F.: Immunohistochemical Detection of the Cytoskeletal Components of the Gastric Parietal Cells. Acta Histochem. Cytochem. 2005; 38(5): 331-337.

54. Wallace, J.L.: NSAIDS and gastric mucosal protection. Why doesn't the stomach digest itself? Physiol. Rev. 2008; 88(4): 1547-1565.

55. Wong, J.C. and Fiscus, R.R.: Essential roles of the nitric oxide (no)/cGMP/protein kinase G type- $1 \alpha$ (PKG-I $\alpha$ ) signaling pathway and the atrial natriuretic peptide (ANP)/cGMP/PKG-I $\alpha$ autocrine loop in promoting proliferation and cell survival of OP9 bone marrow stromal cells. J Cell Biochem. 2011; 112: 829839.

56. Youmba, B. S.; Belmonte, L.; Galas, L.; Boukhettala, N.; Bole-Feysot, C. Dechelotte, P. and Coeffier, M.: Methotrexate modulates tight junctions through NFKB, MEK and JUK pathways. J Pediatr Gastroenterol Nutr. 2012; 54(4): 463-470.

57. Zandifar, E.; Sajedeh, S. B.; Zandifar, A. and Shaghayegh, J.: The effect of captoril on impaired wound healing in experimental diabetes. Int. J. Endocrinol. 2012; 78: 47-52. 